\title{
Prognostic Factors for Cats with Squamous Cell Carcinoma of the Nasal Planum following High-Dose Rate Brachytherapy
}

Dissertation of the Integrated Master in Veterinary Medicine Mafalda Carneiro Lino

Supervisor

Felisbina Luísa P. Guedes Queiroga, DVM, MSc, PhD

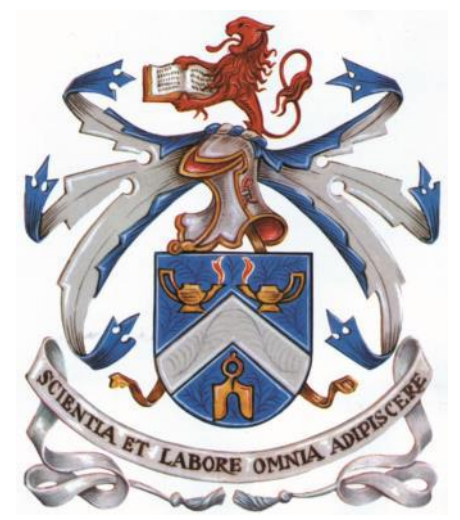

Vila Real, 2017 
Universidade de Trás-os-Montes e Alto Douro

\section{Prognostic Factors for Cats with Squamous Cell \\ Carcinoma of the Nasal Planum following High-Dose Rate Brachytherapy}

Dissertation of the Integrated Master in Veterinary Medicine Mafalda Carneiro Lino

Supervisor

Felisbina Luísa P. Guedes Queiroga, DVM, MSc, PhD

Jury Composition

Vila Real, 2017 


\section{Declaration of personal responsibility for the content presented}

Name: Mafalda Carneiro Lino

Dissertation of the Integrated Master in Veterinary Medicine

Title: Prognostic Factors for Cats with Squamous Cell Carcinoma of the Nasal Planum following High-Dose Rate Brachytherapy

Supervisor: Felisbina Luísa P. Guedes Queiroga, DVM, MSc, PhD

Year of Completion: 2017

I declare that this master dissertation is the result of my research and personal work and the guidance of my supervisor. Its content is original and all sources consulted are duly mentioned in the text and in the references. I further declare that this work was not presented in any other institution to obtain any academic degree.

Vila Real, September 2017

Mafalda Carneiro Lino 


\section{AKNOWLEDGEMENTS}

First and foremost, I would like to express my deepest gratitude to my master advisor Professor Felisbina Queiroga for helping me writing down this work, for advising me on internships, providing me fantastic opportunities and for believing in me so much; for always directing me to make the best decisions and above all for the patience.

I want to thank all the Academy from Universidade de Trás-os-Montes e Alto Douro, especially to all the teachers and veterinarians from HV-UTAD, that helped me reach this goal.

From my first curricular internship, I would like to compliment the amazing team of Centro Hospitalar Veterinário do Porto and acknowledge all the teaching, professionalism and so good work environment, with a special thank you to Dr. Hugo Gregório. I would like to thank Dr. Joana Cardoso, Dr. Catarina Araújo, Dr. Daniela Bento and nurses Stéphanie, Joana, Diana and Filipa for real friendship and kindness, and also the interns who shared this experience with me for the great team work (Bruno, Susana, Lúcia, Inês, Tomás).

I am so grateful I have had the opportunity to learn from Dr. Didier Lanore, such an amazing oncologist of reference in France; I thank him immensely for sharing his knowledge, work and routine at the clinic with me, and for all the fundamental help provided at distance to carry out this work. Also a big merci to all the workers at Clinique Vétérinaire Alliance in Bordeaux, that despite the language tried to help me the most, especially the oncology team which I spent the most time with. A thank you to Dr. Franck Crouzet and Dr. Lanore for letting me access their clinical cases and to Dr Anaïs Combes for teaching me with such care. I also want to thank Dr. Delphine Rivière for all the affection.

Still at Bordeaux, a special thank you to my new french family Julie, Stéphane and little Charlie, who made my stay perfect with all the support and love.

To my oldest friends Ri and Maria, I would like to thank for the good times, the words and strength. I am extremely thankful to my dearest Cátia for the inspiration, the shared pride, for always trying to make me see sense and for all the emotional support. To Isabel and Catarina for the good friendship.

I am so grateful for my university friends, to whom I thank from the heart: my very best house mates and for life friends Carolina and Inês; João, Gabi, Mari, Fá, Rui, Fipa and JóRi for all the group works, moments of fun and growing together; to Rita Quinteira for the friendship, all-time energy and mental power; to Gaspar for the endless help, willingness and motivation; to Glória, Francisca, Andreia, Inês and Catarina (who made me feel a part of the group since 
always) and also my latest house mate Ana Inês, who were the best partners to share the last year, rich in emotions, achievements and companionship.

To Dr. Isabel, a deep thank you for helping me see things from another perspective and make me hold my head up.

This has also a little bit of my loved four-legged Tobias and Charlie for always being the inspiration and the most patient helpers.

I also owe a debt of gratitude to my parents and sister for having tirelessly accompanied my academic career with a never-ending encouragement; for all the trips, all the tupperwares and all the care. A special thank you to my grandmother who always showed so much pride.

Finally, the most heartfelt thank you to my Pedro, for whom there are no words to describe unconditional love and support. 


\begin{abstract}
Squamous cell carcinoma (SCC) is one of the most common malignant tumors of the cats' skin. Higher incidence rates are associated to cats with light-colored fur, lack of protective pigment, and sparsely haired / hairless areas, and so ears, eyelids, nasal planum and temples are most affected areas, and older cats are the most affected. Chronic sunlight exposure is considered the inducing factor of carcinogenesis: it leads to actinic changes on the skin that evolve into pre-neoplastic lesions, carcinoma in situ and finally invasive SCC. Definitive diagnosis is achieved with biopsy.

As the metastatic rate of nasal planum SCC is very low, and given its locally invasive character, the main goal of the treatment is to achieve the best local control of the tumor. Several treatment modalities have been used to manage this tumor but with unsatisfactory outcomes. External radiotherapy has been used over the last years with better results on recurrence times and overall survival. High-dose rate (HDR) brachytherapy is a short-distance radiotherapy treatment, with a short overall treatment time and a sparing effect of the non-neoplastic tissues.

Because of the lack in the literature on HDR brachytherapy to treat this tumor, this retrospective study was performed to find out if there were any individual and tumor's variables that could be prognostic factors for progression-free survival (PFS) and overall survival (OS). Data collected from clinical records of 58 cats with SCC of the nasal planum treated with HDR brachytherapy included: gender, neuter status, breed, age, number of lesions, localization and size of the tumor, tumor extension beyond the nasal planum, ulceration, lymph node and lung metastases, any previous treatment, tumor response to HDR brachytherapy, recurrence and overall survival.
\end{abstract}

The total radiation dose delivered was $30 \mathrm{~Gy}$, administered in five fractions of $6 \mathrm{~Gy}$ for a period of 3 to 4 days. Complete response was achieved in $72 \%(n=36)$ of the cats, partial response in $26 \%(n=13)$ and $2 \%(n=1)$ did not respond. Median PFS and OS times were 316 and 835 days, respectively. The gender of the cats treated with HDR brachytherapy affected OS time $(\mathrm{p}=0.045)$, with male cats living less. Tumor size showed a significant effect on tumor response $(\mathrm{p}=0.015)$ and on OS $(\mathrm{p}=0.001)$, so cats with tumors equal or smaller than $2 \mathrm{~cm}$ achieved better treatment responses and lived longer than cats with larger lesions. Results also reported that cats without tumor extension to the upper lip lived longer ( $\mathrm{p}=0.015)$. Cats that received other treatment before HDR brachytherapy showed shorter PFS times. Finally, tumor response to HDR brachytherapy was found to be statistically associated with PFS ( $\mathrm{p}=0.038$ ) 
and OS $(\mathrm{p}<0.001)$, so cats with better tumor responses showed better local tumor control times and lived longer.

In conclusion, lesions should be treated as soon as possible and can be achieved very good results with HDR brachytherapy in what concerns to PFS, OS and cosmetic outcomes.

Keywords: cat, squamous cell carcinoma, nasal planum, brachytherapy, prognostic factors. 


\section{RESUMO}

O carcinoma de células escamosas (SCC) é um dos tumores malignos mais comuns da pele dos gatos. A incidência é maior em gatos com pêlo de cor clara, falta de pigmento e áreas de pêlo escasso ou sem pêlo, e as orelhas, pálpebras, plano nasal e têmporas são as áreas mais afetadas, sendo mais comum nos gatos mais velhos. A exposição solar crónica é considerada o fator indutor da carcinogénese: induz alterações actínicas na pele que evoluem para lesões préneoplásicas, carcinoma in situ e SCC invasivo. O diagnóstico definitivo é feito por biópsia.

Como a taxa de metastização do SCC do plano nasal é muito baixa, e dado o seu caráter localmente invasivo, o principal objetivo do tratamento é o controlo local do tumor. Várias modalidades de tratamento são utilizadas no maneio deste tumor, mas com resultados pouco satisfatórios. A radioterapia externa tem sido usada nos últimos anos com melhores resultados nos tempos de recidiva e sobrevida global. A braquiterapia de alta dosagem (HDR) é um tratamento de radioterapia de contacto, com um curto período de tratamento global e um efeito poupador dos tecidos não neoplásicos.

Devido à falta de literatura sobre braquiterapia HDR no tratamento deste tumor, este estudo retrospetivo foi realizado para descobrir se existiam variáveis individuais e do tumor que pudessem ser fatores de prognóstico para a sobrevida livre de progressão (PFS) e sobrevida global (OS). Os dados recolhidos são referentes a 58 gatos com SCC do plano nasal tratados com braquiterapia HDR, e incluem: género, estado reprodutivo, raça, idade, número de lesões, localização e tamanho do tumor, extensão do tumor para além do plano nasal, ulceração, metástases ganglionares e pulmonares, qualquer tratamento prévio, resposta à braquiterapia HDR, recidiva e sobrevida global.

A dose total de radiação foi $30 \mathrm{~Gy}$, administrada em cinco frações de $6 \mathrm{~Gy}$, durante 3 a 4 dias. Resposta completa foi alcançada em $72 \%(n=36)$ dos gatos, resposta parcial em $26 \%$ $(n=13)$ e $2 \%(n=1)$ não responderam. A média dos tempos de PFS e OS foram 316 e 835 dias, respetivamente. O sexo dos gatos tratados com braquiterapia HDR afetou o tempo de OS $(\mathrm{p}=0,045)$ : os machos viveram menos tempo. O tamanho do tumor mostrou um efeito significativo na resposta ao tratamento $(\mathrm{p}=0,015)$ e na OS $(\mathrm{p}=0,001)$ : gatos com tumores iguais ou menores que $2 \mathrm{~cm}$ responderam melhor ao tratamento e viveram mais tempo. Os gatos sem progressão tumoral para o lábio superior viveram mais tempo $(\mathrm{p}=0,015)$. Os gatos que receberam outro tratamento antes da braquiterapia HDR apresentaram tempos de PFS menores. Finalmente, a resposta do tumor à braquiterapia HDR estava estatisticamente associada à PFS 
$(\mathrm{p}=0,038)$ e OS $(\mathrm{p}<0,001)$ : gatos que responderam melhor apresentaram melhores tempos de controlo local do tumor e viveram mais tempo.

Concluindo, as lesões devem ser tratadas o mais rápido possível e podem ser obtidos resultados muito bons com a braquiterapia HDR no que diz respeito à PFS, OS e resultados cosméticos.

Palavras-chave: gato, carcinoma de células escamosas, plano nasal, braquiterapia, fatores de prognóstico. 


\section{GENERAL INDEX}

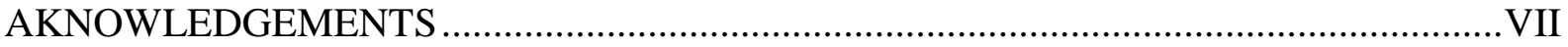

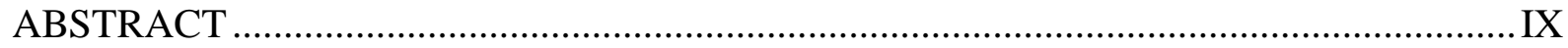

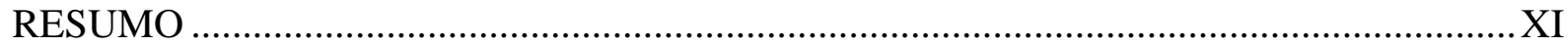

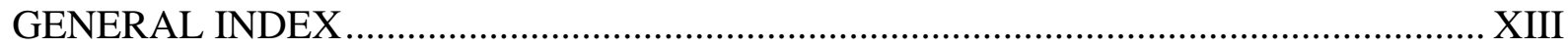

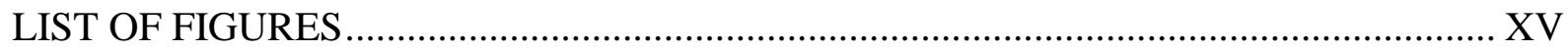

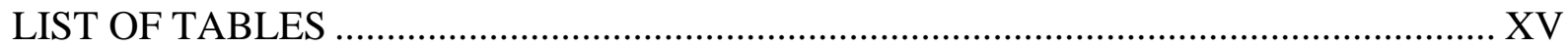

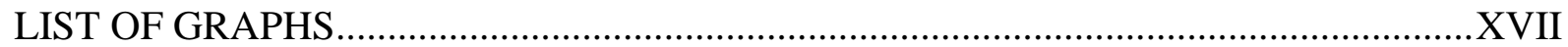

LIST OF ABBREVIATIONS, ACRONYMS AND SYMBOLS ........................................XIX

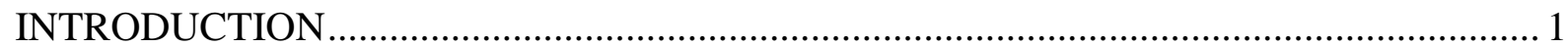

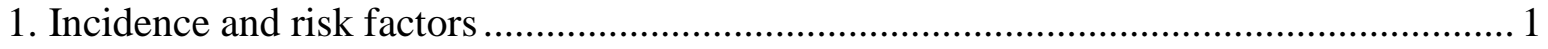

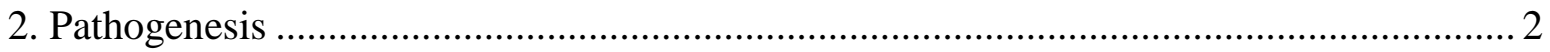

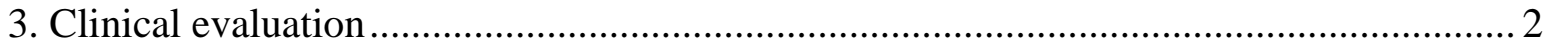

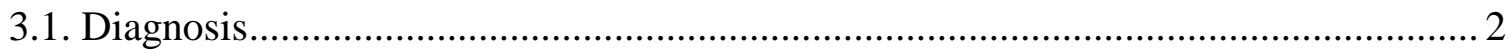

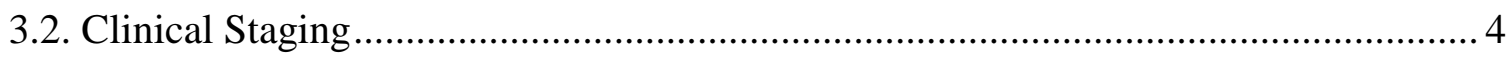

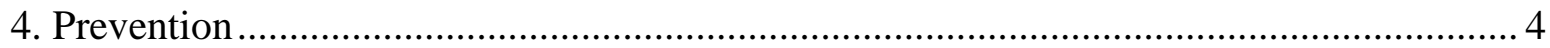

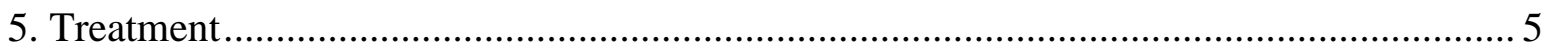

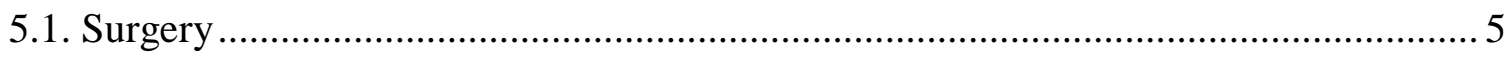

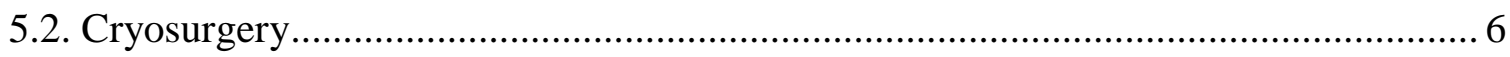

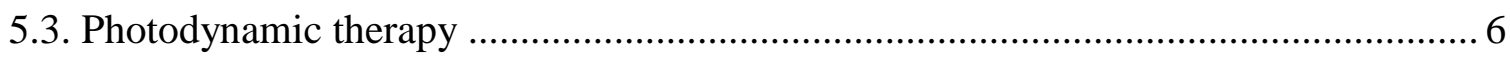

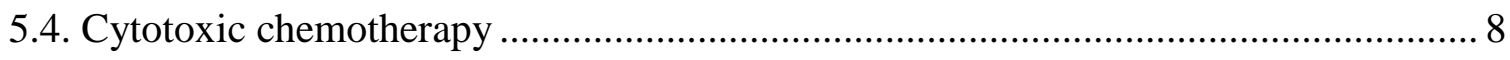

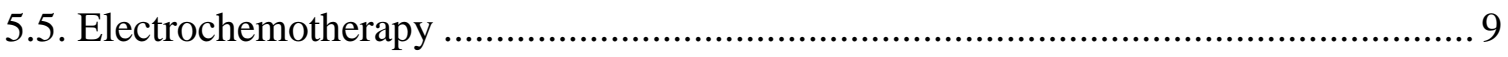

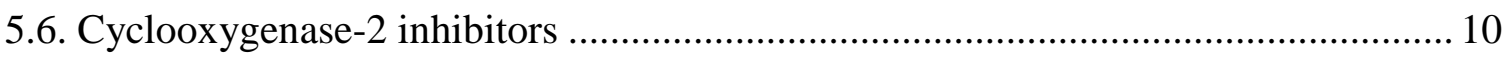

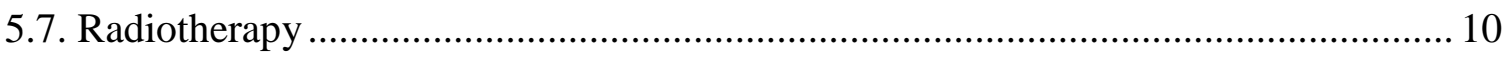

5.7.1. External beam Radiotherapy / Teletherapy ................................................... 12

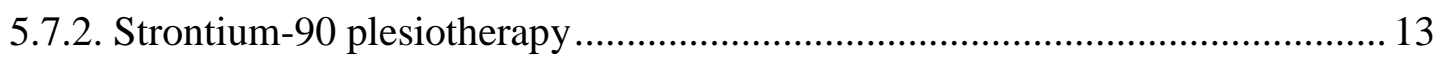

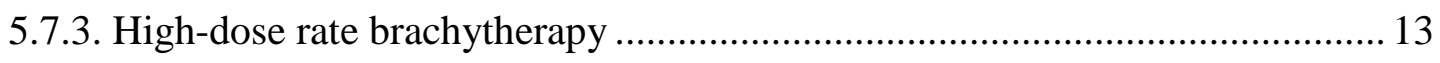

5.7.4. Clinical trials of RT in feline SCC of the nasal planum ............................... 14

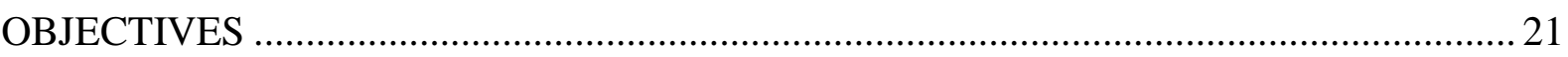

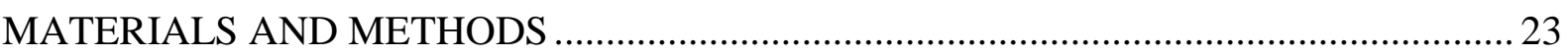

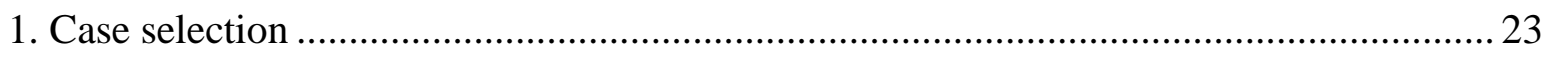

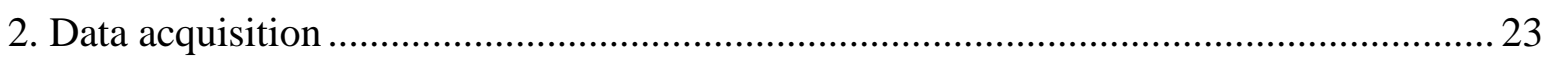

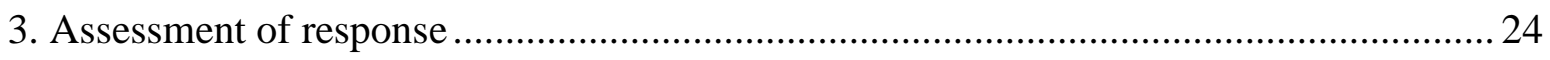




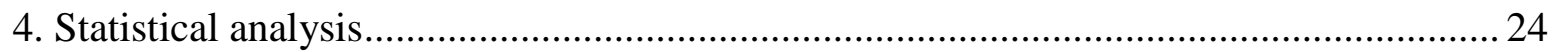

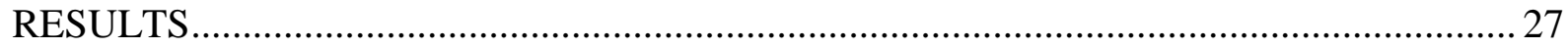

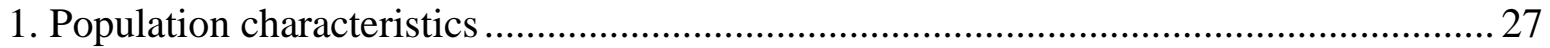

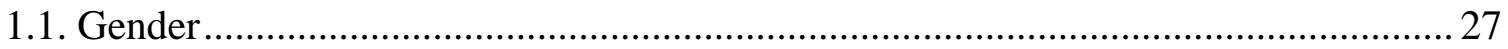

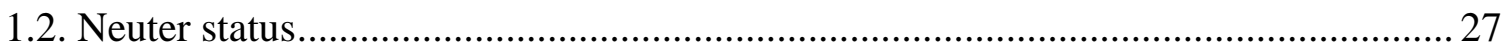

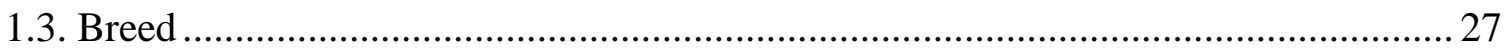

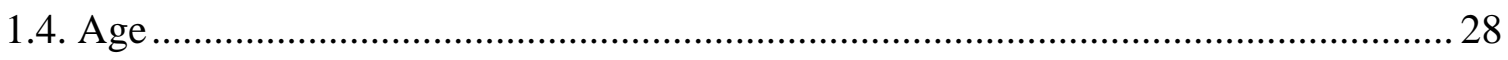

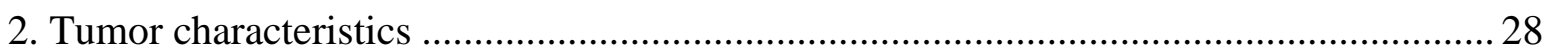

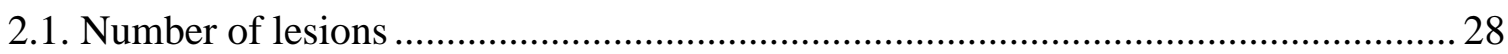

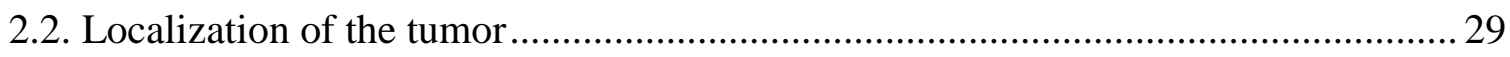

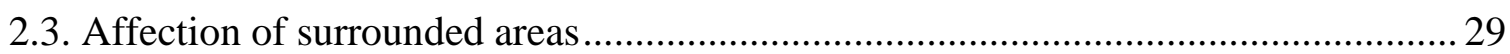

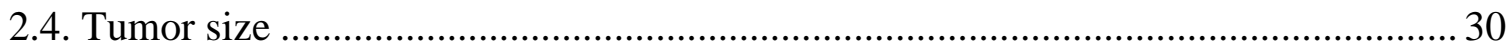

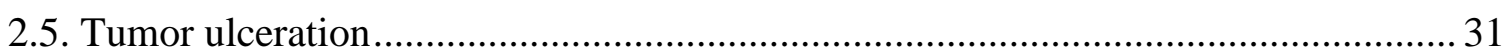

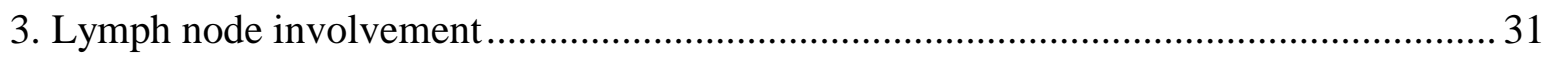

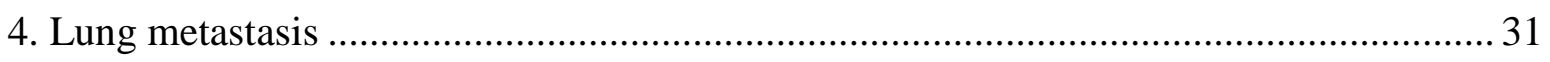

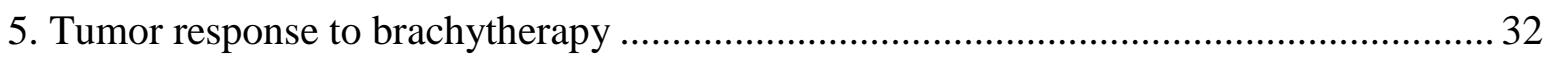

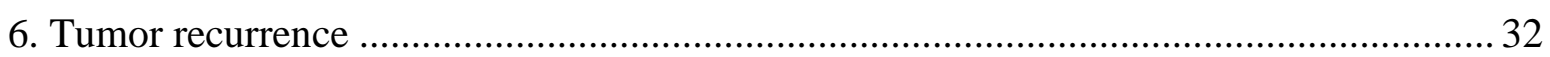

7. Associations between clinical variables and tumor response to brachytherapy ............... 33

8. Associations between clinical variables and tumor recurrence ........................................ 34

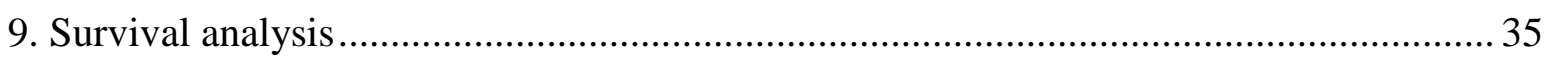

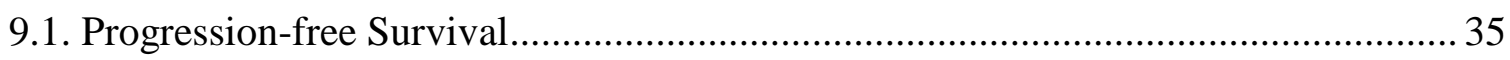

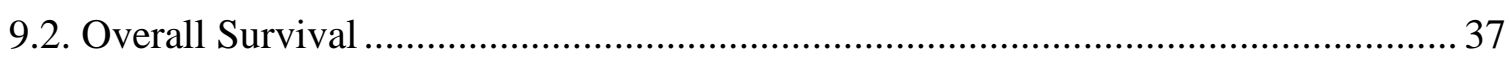

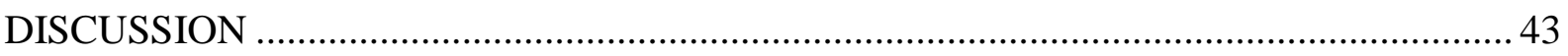

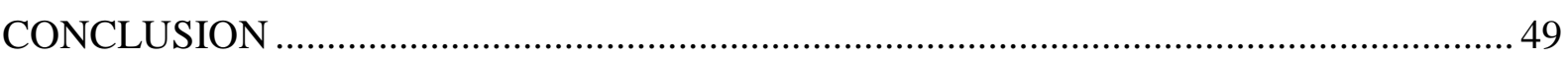

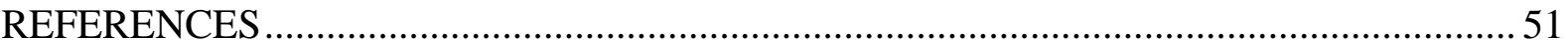




\section{LIST OF FIGURES}

Figure 1 - WHO TNM staging system for skin tumors.................................................. 4

Figure 2 - Acute and late effects of radiotherapy to the skin.............................................. 12

Figure 3 - Considered anatomical localizations of SCC of the nasal planum of the cats of the study

\section{LIST OF TABLES}

Table 1 - Clinical trials of RT in SCC of the nasal planum.

Table 2 - Associations between clinical variables and tumor response to HDR brachytherapy.

Table 3 - Associations between clinical variables and tumor recurrence. 34

Table 4 - Relation between variables and progression-free survival at day 500 and $1000 \ldots . . .36$

Table 5 - Relation between variables and overall survival at day 500 and 1000. 38 


\section{LIST OF GRAPHS}

Graph 1 - Distribution of the population $(n=58)$ by gender.

Graph 2 - Distribution of the population $(\mathrm{n}=56)$ by neuter status.......................................... 27

Graph 3 - Distribution of the population $(n=58)$ by breed. ................................................... 28

Graph 4 - Box and whisker plot of age. The central line corresponds to the mean age 11 years old.

Graph 5 - Distribution of the population $(n=57)$ by number of lesions.

Graph 6 - Distribution of the population $(n=56)$ by localization of the tumor

Graph 7 - Distribution of the population $(n=45)$ by extension of the tumor to hairy skin....... 30

Graph 8 - Distribution of the population $(n=52)$ by extension of the tumor to the upper lip... 30

Graph 9 - Distribution of the population $(n=48)$ by tumor size 30

Graph 10 - Distribution of the population $(n=55)$ by tumor ulceration. 31

Graph 11 - Distribution of the population $(n=50)$ by the tumor response to brachytherapy.... 32

Graph 12 - Distribution of the population $(n=43)$ by recurrence.

Graph 13 - Kaplan-Meier curve comparing progression-free survival of cats treated with HDR brachytherapy without (blue) and with (green) a previous treatment; $\mathrm{p}=0.043$.

Graph 14 - Kaplan-Meier curve comparing progression-free survival of complete (blue) or partial (green) tumor response to HDR brachytherapy; $\mathrm{p}=0.038$.

Graph 15 - Kaplan-Meier curve comparing overall survival of male (blue) and female (green) cats treated with HDR brachytherapy; $\mathrm{p}=0.045$.

Graph 16 - Kaplan-Meier curve comparing overall survival of cats without (blue) and with (green) extension of the tumor from the nasal planum to the upper lip, treated with HDR brachytherapy; $\mathrm{p}=0.015$.

Graph 17 - Kaplan-Meier curve comparing overall survival of cats treated with HDR brachytherapy with a tumor size equal or smaller than $2 \mathrm{~cm}$ (blue) and larger than $2 \mathrm{~cm}$ (green); $\mathrm{p}=0.001$

Graph 18 - Kaplan-Meier curve comparing overall survival of complete (blue), partial (green) or progressive (golden) tumor response to HDR brachytherapy; $\mathrm{p}<0.001$. 41 


\section{LIST OF ABBREVIATIONS, ACRONYMS AND SYMBOLS}

5-ALA - 5-aminolaevulinic acid

AK - actinic keratosis

BISC -Bowenoid in situ carcinoma

BNCT - boron neutron capture therapy

BPA-BNCT - Boronophenylalanine mediated boron neutron capture therapy

CI - confidence interval

COX-2 - cyclooxygenase-2

$\mathbf{C R}$ - complete response

CT - computed tomography

DFI - disease free interval

DFS - disease free survival

DNA - deoxyribonucleic acid

ECT - electrochemotherapy

FIV - feline immunodeficiency virus

Gy - gray (unit)

HDR - high-dose rate

LDR - low-dose rate

LED - light-emiting diodes

MRI - magnetic resonance imaging

MSCCIS - multicentric squamous cell carcinoma in situ

NR - no response

NSAIDs - nonsteroidal anti-inflammatory drugs

OS - overall survival

PD - progressive disease

PDT - photodynamic therapy

PDR - pulsed-dose rate

$\mathbf{P F}$ - proliferative fraction

PFS - progression free survival

$\mathbf{P R}$ - partial response

PV - papillomaviruses

RT - radiotherapy 
SCC - squamous cell carcinoma

Sr-90 - Strontium-90

TNM - tumor, nodes, metastasis

TTP - time to progression

TTR - time to recurrence

UV - ultraviolet

VRTOG - veterinary radiation therapy oncology group

WHO - World Health Organization 


\section{INTRODUCTION}

About $25 \%$ of cats' tumors are skin and subcutaneous neoplasias, and more than $50 \%$ are malignant. ${ }^{1}$ Squamous cell carcinoma (SCC) is one of the most common malignant tumors of the skin of cats (about 15\%). Around 10\% of these skin SCC occur in a variant form known by multicentric squamous cell carcinoma in situ (MSCCIS) or Bowenoid in situ carcinoma (BISC) due to its histological similarity to human's Bowen's disease. ${ }^{2-4}$

\section{Incidence and risk factors}

The development of cutaneous SCC is strongly related to sunlight exposure: ultraviolet (UV) radiation, especially the B portion (UV-B), can cause skin damage if the fur or pigmentation do not grant an adequate protection to the skin by reflecting the light and preventing it to reach the skin surface. ${ }^{1,5-8}$ Therefore, higher incidence rates are associated to cats with light-colored fur, lack of protective pigment, and sparsely haired / hairless areas like the ears, eyelids, nasal planum and temples, which make these the most affected areas. ${ }^{2,8,9}$ Other environmental factors, such as the atmospheric conditions and the geographic location of the cats, contribute to the difference of incidence rates: cats inhabiting globe zones near to the equatorial line will be more exposed to the risk when compared to those living farthest, above or below the equator, as seen with humans in what concerns to skin cancer induced by sunlight. ${ }^{8}$

Squamous cell carcinoma of the nasal planum is relatively common in the cat. ${ }^{9}$ Cats with white fur have a risk to develop head and neck SCC 13.4 more times than cats with dark fur. ${ }^{10}$ Papillomavirus (PV) is also thought to be involved in the development of this tumor in cats, especially in BISC lesions. $2,4,9,11$

Older cats are the most affected by SCC, with a median age of 10 to 12 years. There is no sex or breed predisposition, although it is known that light-colored and short-haired breeds are more susceptible in contrast to long-haired breeds; also Siamese cats are considered naturally protected due to their pigmentation on the most affected areas. ${ }^{2}$

Cats infected with feline immunodeficiency virus (FIV) were thought to be more prone to the development of SCC, but there are studies reporting that their responses to radiotherapy do not differ from those of the non-infected cats, and times of tumor control and survival were not affected, so the FIV infection status should not be an hindrance when it comes to treatment. ${ }^{7,12}$ However, these cats are considered of higher risk to more severe radiation side effects, showing more exuberant reactions at the irradiated area. ${ }^{7}$ 


\section{Pathogenesis}

Chronic exposure to UV-B radiation is considered the inducer of photocarcinogenesis, and later tumor progression is associated with individual characteristics. ${ }^{7}$ Solar dermatosis could be the first signal of a skin tumor development. Chronic solar radiation exposure induces actinic changes on the skin, beginning with a sunburn and evolving into pre-neoplastic lesions - actinic keratosis (AK), followed by carcinoma in situ (pre-invasive) with possible evolution to invasive SCC if the integrity of epidermal basal membrane is compromised. ${ }^{8,13}$ Different stages of evolution of the disease can be observed in the same area at the same time. Hammond $\boldsymbol{e t}$ al. ${ }^{12}$ reported that $33 \%$ of the cats with nasal planum SCC under treatment developed new lesions. That is not surprising since all the body is exposed to the same amount of solar radiation and so it is possible the coexistence of lesions at different stages of development.

Bowenoid in situ carcinoma is manifested by multifocal superficial hyperpigmented and crusty plaques (with gradual thickening and posterior ulceration ${ }^{14}$ ) in any part of the cat's body, without any relation to the amount of fur nor his color, suggesting that it has no relation with UV radiation exposure. ${ }^{2,14,15}$ This disease is usually benign (although it may progress to invasive SCC) and some cases are linked to PV infection. ${ }^{14}$ According to Munday et al. ${ }^{11}$ BISC can be a neoplastic transformation of a viral plaque induced by PV; in their study PV DNA and increased p16 protein were detected within the SCCs UV-protected, in contrast with UVexposed SCCs since these presumably develop from actinic keratosis lesions.

\section{Clinical evaluation}

\subsection{Diagnosis}

In case of solar induced SCC, numerous lesions can be detected coexisting at the same time, although at different stages: solar dermatitis, pre-cancerous lesions (actinic keratosis), carcinoma in situ and invasive SCC. In case of actinic keratosis, changes are consistent with chronic solar exposure: solar elastosis, skin thickening plaque-like, epithelial desquamation and curling in the specific case of the ears. ${ }^{8,16}$

Cats with SCC of nasal planum usually attend to the consultation because the owner noticed a lesion that is not healing, and less often due to actinic changes. SCC can appear as a single lesion or as multiple lesions, generally in the format of a superficial erosion, then an ulcer and, in more advanced stages, invasive crateriform lesions, preceded by a protracted course. They can have a plaque form, papillary form or fungiform. They can also be nodular or proliferative, 
and erythema is often observed, as well as scales, scabs and or swelling. ${ }^{2,5,17-22}$ Depending on the extension of the mass, serous, mucoid or purulent discharge, epistaxis, sneezing, dyspnea, stertorous breathing and facial deformation can be observed in addition. ${ }^{17,21}$

Anamnesis should be performed in order to know the complete clinical history. Information about date of first identification of the lesion, current size, rate of growth and presence of adherences and ulceration must be collected. ${ }^{5}$ Additionally, during physical examination the regional lymph nodes should be examined in order to detect any alteration. Cytology of regional lymph nodes is also recommended in case of enlargement or painful on palpation.

Radiography of the nose, under anesthesia, can be used to identify characteristics already known as been related to malignancy, such as tissue opacification and changes compatible with bone lysis. However, x-ray has low specificity and sensibility, and so computed tomography (CT) is the imaging test of choice to evaluate the extension of the tumor. ${ }^{17}$ In any case, diagnosis should never be presumptive based on the CT images since there are evidences that nasal neoplasia and rhinitis share CT characteristics that prevent imaging distinction. ${ }^{23}$ Magnetic resonance imaging (MRI) could help to better analyze a possible brain injury due to extension of the tumor when the mass crosses the cribriform plate. ${ }^{17}$

Definitive diagnosis of SCC is achieved with biopsy (either multiple punch biopsy or incisional or excisional biopsies) as histopathology is fundamental to evaluate the behavior of the tumor, the degree of differentiation, cellular morphology and vessel invasion. ${ }^{1,2,5}$ Additionally, with the assessment of regional and distance metastases, it is possible to establish the clinical stage, recommend the most adequate treatment protocol and predict prognosis. Cytology with fine needle aspiration is not the most adequate methodology for diagnosis due to the superficial nature of the majority of nasal planum SCC, and also due to the inflammation and bleeding commonly associated. ${ }^{2}$ Although it is easy and brief, cytology identification of the cell type is possible but it is not diagnostic ${ }^{1,17}$. So, to avoid inaccuracy, in cases where only cytology is allowed, the tumor should not be fit in a T stage just by visual measurement of the lesion and assumption of the invasiveness.

Although the TNM classification system proposed by the World Health Organization $(\mathrm{WHO})^{24}$ (Figure 1) dates back to 1980, it is still used and referenced in recent publications ${ }^{2,5,25}$. 


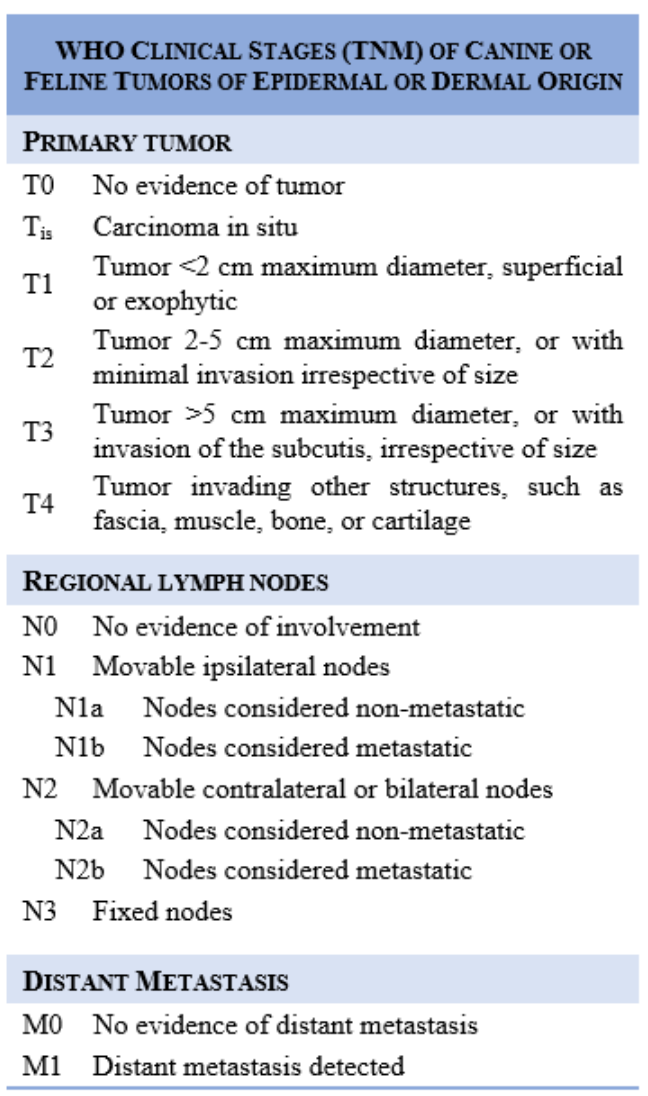

Figure 1 - WHO TNM staging system for skin tumors. Adapted from Hauck et al. ${ }^{5}$

\subsection{Clinical Staging}

\section{Primary tumor assessment}

Lesions should be direct measured at their larger diameter. However this could be hard for larger or more invasive lesions, and so the measurement and extension assessment should be done with the help of a CT scan. $^{5}$

\section{Regional lymph nodes assessment}

Regional extension should be assessed by cytology after a fine needle aspiration of the lymph nodes, even if they do not seem enlarged or reactional on palpation. ${ }^{1}$ If the results of cytology are unreliable or shady, an histology of the lymph node by biopsy should be carried out to clear the doubts. $^{5}$

\section{Distant metastasis assessment}

The distant extension of a tumoral process should be done when in presence of a malignant neoplasia to detect metastasis. Chest radiographs in three views are the most used, but a CT scan could also be done in place of the first. ${ }^{2,5}$

In the original WHO publication ${ }^{24}$ a stage grouping was not specified. With all the modifications and adaptations from the original, and as regional and distant metastases are very rarely observed, SCC of the nasal planum is commonly staged based on tumor size and invasiveness degree, considering just the $\mathrm{T}$ letter from the assessment of the primary tumor (stage $\mathrm{T}_{\text {is }}$ and stage $\mathrm{T} 1$ to $\left.\mathrm{T} 4\right) .{ }^{7,12,15,26-29}$

\section{Prevention}

Solar induced SCC can be prevented through owner's education. Light-colored and shorthaired cats should avoid sunlight exposure, at least in the hours of the highest incidence of radiation. ${ }^{1,2,9,10,20,30}$ If it is an indoor cat that could be easier to control, even with UV light blocking films for windows. ${ }^{2}$ 
Topical sunscreens rarely help when in the nasal planum, as it is quite impossible to no be licked off. ${ }^{9,10,26}$

Tattooing to add protective pigment to the skin is not proven to be effective, since the tattoo is applied to the dermis, and the SCC arise from the squamous epithelium of the epidermis. ${ }^{2,9,10,30}$ Thomson $^{30}$ suggests that henna tattoos could protect from some of the solar damage as they are applied superficially to the epidermis in despite of the need to reapplications.

Vitamin A synthetic derivatives like 13-cis-retinoic acid and etretinate were used to increase epithelial differentiation, and it was concluded that these substances can help managing preneoplastic lesions, controlling their progression. ${ }^{9,10}$

\section{Treatment}

For a long time in veterinary medicine, anticancer treatment was practically based on surgery, and only over the last decades, new protocols, techniques and methodologies were extrapolated from the human medicine and started to be applied. ${ }^{31}$

The main goal of treating nasal planum SCC is to achieve the best local control of the tumor, given its locally invasive character and low metastatic rate. ${ }^{17}$ In this regard, treatment approach is usually chosen according to the tumor clinical stage. ${ }^{2}$ After a complete staging of the disease the therapeutic strategy could be established, and decided of what intent would it be: curative, adjuvant or palliative. ${ }^{31}$

\subsection{Surgery}

Surgical excision, if feasible should be the first approach to cutaneous SCC. ${ }^{5}$ However, in tumors of the nasal planum, due to the complex anatomical localization and depending on the level of invasion, performing a complete tumor excision with proper margins (at least $5 \mathrm{~mm}$ ideally) could be difficult. ${ }^{17,30}$ For early stages and superficial lesions of nasal planum SCC surgery alone could be curative if a complete excision is achieved, with better tumor control times than if first treated with external beam radiotherapy. ${ }^{10,20}$ Nonetheless, for advanced tumor stages surgery is also the treatment of choice - a complete resection / planectomy in this case, to have a chance of totally remove the tumor. ${ }^{2,10,22}$

In a study published in 1990 by Withrow et al. ${ }^{32}$ nine cats with nasal tumors were submitted to a complete excision of the nasal planum, and even so, in three cats with SCC the tumor relapsed; the other remained tumor-free till the end of follow-up. In another study ${ }^{10}$, in cats that 
underwent a complete resection of the nasal planum, recurrence was not observed; however, in $29 \%$ of the cats with incompletely resected nasal planum, recurrence was observed.

Nasal planum resection has good prognosis and has proved to be functional in cats, with relative good esthetic results, yet sometimes challenging to the owner's acceptance. Surgery also allows histopathological analysis of the margins, does not need special facilities (like for radiotherapy), and the total treatment time is very short. ${ }^{2,10}$

Taking all the above into account, and knowing that nasal planum SCC could be successfully treated with radiation therapy and with better cosmetic outcomes, surgery is not always considered. ${ }^{5}$

\subsection{Cryosurgery}

Cryosurgery is an alternative treatment for small SCC lesions, and it consists on freezing and thawing the abnormal tissue to destroy it, by the local application of a cryogen (liquid nitrogen or nitrous oxide). ${ }^{2,30}$ Rapid freezing to $-20^{\circ} \mathrm{C}$ is used to form intracellular and extracellular small ice crystals that will damage cell membranes, followed by a slow thawing that causes the formation of bigger crystals by the recrystallization of the smaller ones, maximizing the tissue fragmentation. ${ }^{30,31}$ Three cycles of consecutive freezing-defreezing should be performed and a safety margin of $10 \mathrm{~mm}$ should be included in the treatment field..$^{30,31}$ For bigger lesions (greater than $5 \mathrm{~mm}$ ) is difficult to ensure that the entire tumor is destroyed and the margins are clear, and for this reason local recurrence rates are high (73\% of the cats in one study recurred, with a median time to recurrence (TTR) of 184 days). ${ }^{30}$ In another study, SCC on the pinnae and eyelids responded better to cryosurgery than those of the nasal planum, and for the last ones cryosurgery was not enough, with a median TTR of 254 days. $^{2}$ In conclusion, cryosurgery is cost-effective and readily accessible but has shorter tumor control times when compared to surgery or radiotherapy. ${ }^{20}$

\subsection{Photodynamic therapy}

Photodynamic therapy (PDT) consists in the intravenous, topical or oral administration of a photodynamic agent (photosensitizer) for which tumor cells are the target by selective accumulation, and later the lesion undergoes a specific wavelength light to activate the photosensitizer that induces cell death through oxygen and other free radicals production, as well as tumor vasculature damage; it is performed under anesthesia and analgesia. ${ }^{2,33-35}$ Is has 
been used in human medicine as a recognized treatment but in veterinary medicine so far it is not well established, but the major applicability it has been for feline SCC. ${ }^{34,35}$ PDT is considered effective as a single modality treatment for early stages of SCC because results are conditioned by the depth of penetration of both photosensitizer and light (maximum depth of $1.5 \mathrm{~cm})^{2,34,35}$

Although the good esthetic outcome for cats' nasal planum and the sparing effect of the normal tissue there could be minor adverse effects, such as acute erythema, and edema, and increased heart rates associated with injection site pain, even with analgesia and anesthesia, already reported in human patients that underwent PDT with meta(Tetrahydroxyphenyl)Chlorin (m-THPC; Foscan $\left.{ }^{\circledR}\right) .{ }^{2,34,36}$ Acute effects can be observed during and immediately after the treatment and are usually solved in 3 to 5 days, except in the cases of facial edema outside the treatment area that can cause dyspnea and respiratory stertors, taking longer to heal. ${ }^{36} \mathrm{~A}$ scab develops on the treated area and will last for a few weeks; tissue necrosis following PDT is not very common and rarely ocurrs. ${ }^{34-36}$ Additional care must be taken to avoid direct sunlight exposure after treatment with an intravenous photosensitizer (due to generalized light sensitivity), an Elizabethan-collar must be used to avoid post treatment selftrauma, and also provide supportive therapy to avoid or control secondary infections of the treated field. ${ }^{35-37}$

PDT can be performed with different photosensitizers and light sources. ${ }^{33}$ In a study by Magne et al. ${ }^{36}$ PDT was performed with an intravenous photosensitizer (pyropheophorbidealpha-hexyl-ether) and a laser light source in feline facial SCC: 49\% (30/61) achieved a complete response (CR), 12\% (7/61) a partial response (PR) and 39\% (24/61) did not respond, with a 1-year local control rate of $61.7 \%$; adverse effects were minimal and chronic alopecia was reported in all the cats. In this same study from 1997 was concluded that response and local control rates were significantly associated with tumor stage, proving once again the effectiveness of PDT for superficial SCC.

Later, in 2001, Stell et al. ${ }^{38}$ performed PDT with a topical (cream) photosensitizer (5aminolaevulinic acid, 5-ALA) and a light-emitting diodes (LED) light source with CR in 9/10 cats with nasal planum SCC, with a complete response rate of $85 \%$ for $\mathrm{T}_{\text {is }}$ and $\mathrm{T}_{1}$ lesions with a single treatment. Hematological and hepatotoxicity associated with 5-ALA were avoided by its administration topically instead of intravenously; only discomfort on the tumor site was observed and managed with a lidocaine/prilocaine cream and opioids. ${ }^{35}$ 
In 2007 Buchholz et al. ${ }^{34}$ used a laser light source with an intravenous newly developed liposomal photosensitizer (new liposomal formulation of m-THPC) that improves the tropism to the tumor cells sparing the normal ones, and decreases the generalized light sensitivity time. This study revealed to be well tolerated and very effective with $100 \%$ of CR $(n=20)$, recurrence of $20 \%$ and a 1-year local control rate of $75 \%$, greater than the one reported by Magne et al. ${ }^{36}$.

With the same protocol used by Stell et al., in 2008 Bexfield $\boldsymbol{e t}$ al ${ }^{33}$ performed PDT in a larger group of cats with nasal planum SCC. A clinical benefit was observed in 96\% (53/55) of the cats, with $85 \%(47 / 55)$ achieving a CR; $51 \%$ recurred with median disease free survival (DFS) of 157 days.

One year after, Ferreira $\boldsymbol{e t} \boldsymbol{a l}^{37}$ administered an intravenous photosensitizer (hematoporphyrin) and used a LED light source to treat highly invasive as well as noninfiltrative nose and nasal planum SCC in cats. The first ones did not respond to two applications of PDT, and clinical response was only achieved after surgical excision of the tumor; the second ones responded with PR to one application of PDT and CR to two applications. The use of this photosensitizer allows local tumor control to early stages of the disease and can also be used with surgery for more advanced stages of SCC to reduce recurrence times.

In conclusion, PDT can be an alternative to other modalities on the management of nasal planum SCC in cats, despite the still relative short local tumor control after a good response to a single treatment, which can be improved with the development of more selective photosensitizers. ${ }^{2,33,34}$ While awaiting more efficient drugs PDT can be considered in a multimodal therapeutic approach. ${ }^{37}$ However, PDT in pets turns out very expensive and is only performed in a few institutions, and this is a reason why this treatment approach is still unknown to many veterinarians. ${ }^{35}$

\subsection{Cytotoxic chemotherapy}

The information available about the use of cytotoxic drugs in nasal planum SCC of the cats is limited, and relies mostly on intralesional chemotherapy and electrochemotherapy. Performing a chemotherapy is a more invasive treatment approach than the conservative options such as radiation or photodynamic therapy, but the cost is smaller, it does not require specific facilities nor expensive equipment, and it is more easily accessible.

Intratumoral chemotherapy consists in the deeper infiltration of a cytotoxic drug right in the neoplastic tissue and in the surrounding healthy tissues, allowing an increased drug 
concentration in the tumor. ${ }^{39,40}$ Carboplatin started to be used for intratumoral treatments in cats after therapeutic gains were observed with cisplatin in other species; knowing the pulmonary and nephrotoxicity of this drug in cats, carboplatin is the less toxic alternative drug from the same group that also presents activity against carcinomas. ${ }^{40,41}$ In 1996 , Théon et al.$^{40}$ diluted carboplatin in purified sesame seed oil to act as a slow-release formulation by limiting carboplatin release from the injection point and therefore limiting the systemic absorption of the drug, avoiding general adverse effects. In this study administrations were performed weekly, and this treatment showed to be effective since CR was achieved in $73.3 \%$ (11/15) of the cats, with a progression-free survival (PFS) of 16 months and 1-year survival rate of $55.1 \%$.

The study published by de Vos et al. ${ }^{39}$ in 2004 (discussed in section 5.7.4.) combined superficial x-rays RT with intralesional administration of carboplatin to treat feline SCC of the nasal planum; here carboplatin was used as a radiopotentiating agent for radio-chemotherapy which has more power administered intratumoral than intravenously. Treatment was well tolerated and all the cats of the study achieved CR, a promising result considering the advanced stage of the tumors treated.

Individual protection equipment should be used when performing injection of intratumoral carboplatin due to the hazard of aerosol formation if it sprays back from the needle to the air or surrounding surfaces. ${ }^{2,39}$ A leakage of the cytotoxic from the tumor is also possible to happen and it should be cleaned with absorbent paper. ${ }^{39,40}$

Intravenous mitoxantrone is also mentioned in the literature for malignant tumors of the cats but with a low response rate $(4 / 32$ cats $) .^{2}$

\subsection{Electrochemotherapy}

Electrochemotherapy (ECT) consists in the administration of a cytotoxic drug (like bleomycin or cisplatin) in association with high-voltage electric pulses that stimulates the drugs to enter into the tumor cells changing their permeability. ${ }^{25,42}$

Bleomycin is an antibiotic with cytotoxic properties that is indicated in the treatment of SCC. ${ }^{41}$ ECT with intratumoral bleomycin is reported in 2009 by Spugnini et al ${ }^{42}$ as a safe and effective treatment modality for feline SCC. After the tumor and margins injection with bleomycin, biphasic electric pulses were delivered by electrodes. After two sessions of ECT with 1 week interval, of the 7 cats with nasal planum tumor, 6 achieved CR and 1 PR, and 4 were still in remission at the end of follow-up. 
In 2014, Tozon et $\boldsymbol{a l}^{25}$ published a study of electrochemotherapy with intravenous bleomycin with $87.5 \%$ of CR, with recurrence in one of 5 cats with nasal planum SCC. The cosmetic effect is also very good and much more well accepted when compared to surgical resection of the nasal planum, and there are almost none adverse effects, reasons why the ECT could also be considered to manage these lesions. ${ }^{25}$

\subsection{Cyclooxygenase-2 inhibitors}

It is still unknown the role of Cyclooxygenase-2 (COX-2) inhibitors on the prevention and management of SCC of the nasal planum, and further investigation is needed.

COX enzymes has been associated with neoplastic formation and tumor growth, and while isoenzyme COX-1 is involved in physiologic processes, the isoenzyme COX-2 can be induced to produce prostaglandins which affect pathologic processes (inflammation, wound healing and tumor development). ${ }^{2,43,44} \mathrm{COX}-2$ was the target of the studies since it is overexpressed in humans with SCC UV-light induced, AK in human is treated with COX-2 inhibitors, the risk of developing AK lesions or even an epithelial tumor is lower in humans treated with nonsteroidal anti-inflammatory drugs (NSAIDs) COX-2 specific, and COX-2 was detected in canine SCC. ${ }^{2,43,44}$ Beam et $\boldsymbol{a l}^{43}$ observed that COX-2 was not detected for none of the cutaneous SCC in cats, suggesting a species difference of COX-2 expression in canine and feline neoplasia or a feline COX-2 concentration lower than the immunohistochemistry detection level. Based on this, their conclusion was that COX-2 inhibitors would not have an anticancer activity for cats.

In contrast, in a study performed by Bardagí $\boldsymbol{e t} \boldsymbol{a l} .{ }^{44}$ in 2012, it is demonstrated a strong COX-2 expression in feline AK lesions, SCC and inflammatory dermatosis, raising again the issue of the use of COX-2 inhibitors in these cases.

\subsection{Radiotherapy}

Ionizing radiation is used in anticancer therapy through two major types: photon radiation (x-rays and gamma rays) and particle radiation (electrons and protons). ${ }^{31,45}$ Radiation acts on the surface or in depth, inducing direct damage to cell DNA or to biological molecules, consequently affecting cellular division, growth and lesion repair capacity; this way, radiation can be used to kill neoplastic cells and reduce tumors' volume. ${ }^{28,31,45}$ Radiotherapy (RT) is a 
local treatment without systemic toxicity and the possible side effects, both acute or late, only affect the irradiated field. ${ }^{46}$

The intent of RT could be definitive / curative if there is a high possibility of a long-term tumor control, adjuvant when used in association with other treatment modalities (as surgery or chemotherapy), or palliative in case of advanced disease, when survival maintenance is hopeless but an improvement in cat's quality of life can be achieved ${ }^{31,45}$ Nasal carcinomas in cats are expected to have a good response to hypofractionated radiotherapy for both curative and palliative intents. ${ }^{47}$

Radiotherapy is considered nowadays as the first choice option for radiosensitive tumors, for those difficult to surgically resect and to use in cases of recurrence. ${ }^{31,48}$ However, due to the need of special facilities, trained technicians and elevated costs, radiotherapy is not widely used.

The ionizing radiation can be administered by distinct methods classified in: external beam RT or teletherapy when the radiation source is distanced from the treating field (generally using $\mathrm{X}$ rays, Cobalt-60 or electrons); brachytherapy or curietherapy when the radiation is delivered through a sealed source placed directly in the tumor - on the surface or interstitially (using Cobalt-60, Cesium-137, Strontium-90 or Iridium-192); plesiotherapy, a kind of brachytherapy, that uses a Strontium-90 (Sr-90) applicator to deliver low-energy radiation; and systemic or intracavitary radiotherapy when radioisotopes, or radioisotope molecules, are administered through a non-sealed source (orally or injected), being delivered to the target tissue by own physiological processes (Iodine-131and Samarium-153). ${ }^{28,31,45-47,49}$

Radiotoxicity is related to the radiosensitivity of the irradiated tissues (that is proportional to the mitotic index), and so, depending on the tissue response to radiation, acute or late effects can be observed. ${ }^{31}$ The skin is considered a radiosensitive tissue with fast proliferating cells and therefore acute reactions are more likely to occur. ${ }^{31,46}$ Acute effects occur during the treatment course or within a few days and they are usually self-limiting or completely solved with supportive treatment in two to four weeks; late effects could be observed several weeks or months, or even years, after the treatment, and are usually irreversible. ${ }^{45,50}$ Acute and late effects of RT on the skin are mentioned in Figure 2, adapted from the toxicity criteria of the Veterinary Radiation Therapy Oncology Group (VRTOG) ${ }^{51}$. 


\section{VRTOG SCORE FOR RADIATION MORBIDITY OF THE SKIN}

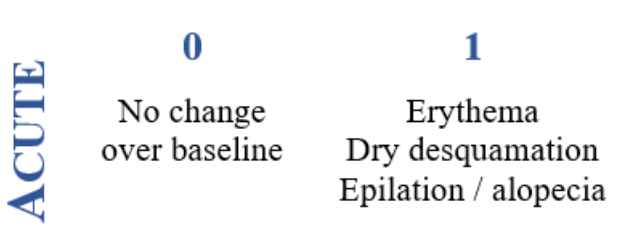

0

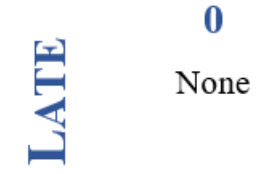

1

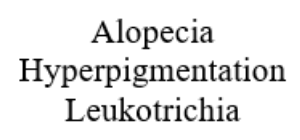

2

Patchy moist desquamation without edema

2

Asymptomatic induration (fibrosis)
3

Confluent moist desquamation with edema and/or ulceration, necrosis, hemorrhage

3

Severe induration causing physical impairment

Figure 2 - Acute and late effects of radiotherapy to the skin. Adapted from VRTOG ${ }^{51}$

\subsubsection{External beam Radiotherapy / Teletherapy}

External beam RT is the most used method of RT in veterinary medicine, adequate to treat superficial and invasive SCC lesions on the nasal planum, using different amounts of energy: the higher the energy, the deeper the radiation penetrates the tissues. Therefore, low penetrating beams (gamma rays from cobalt units) are preferred for superficial tumors, as well as electron beams (from linear accelerators) because of their short penetrating distance despite their highenergy, and high penetrating beams (x-rays from linear accelerators) are preferred for deeper located tumors, or for those with a big volume. This is important when thinking of sparing the non-neoplastic underlying tissues, reducing the occurrence of side effects. ${ }^{46}$

Full-course protocols of external beam RT are usually performed over three to four weeks, during which multiple fractions of radiation are given, for both superficial and deep lesions. The literature reports that tumors with small volume respond better to external RT; in a study is also concluded that there is no difference between tumor stages T2, T3 and T4 in what concerns to response to radiotherapy. ${ }^{7}$ Other survival data will be developed in section 5.7.4., where clinical trials of RT in feline SCC of the nasal planum are discussed.

Although the reports of numerous protocols, the outcomes are similar among them: the cosmetic results are good when compared to surgery, recurrence rate is high and too many anesthesias are needed. 


\subsubsection{Strontium- 90 plesiotherapy}

Plesiotherapy consists in the direct application of Sr-90 on the surface of the lesion with an ophthalmic probe. This method showed efficacy in the management of ocular SCC in humans. ${ }^{26}$ This treatment modality is adequate for superficial lesions because the dose decreases with depth (only less than $10 \%$ of the maximal dose delivered at the surface will penetrate to a depth of $3 \mathrm{~mm}$ ) and therefore, lesions with more than $2 \mathrm{~mm}$ should not be considered for this modality. ${ }^{2,10,12,26,52}$ Van Vechten et al. ${ }^{52}$ (abstract from 1993), Goodfellow et al. ${ }^{26}$ (2006) and Hammond et al. ${ }^{12}$ (2007) reported the successful use of Sr-90 plesiotherapy in cats with nasal planum SCC with, in the last two publications, 13/15 cats and 43/49 cats achieving CR; more results on this topic are also presented in clinical trials' section (5.7.4.).

\subsubsection{High-dose rate brachytherapy}

Brachytherapy is a method of delivering radiation at short distance, through a sealed source (radioactive seeds or wires) placed directly in the tumor - interstitially, temporarily or permanently, delivering radiation continuously as the source deteriorates. ${ }^{46,47,49,53}$

Small size and well delimited tumors, tumors non-amenable for surgical excision and tumors with high recurrence rates can benefit from brachytherapy. ${ }^{54}$

Iridium-192 was the most used radioisotope in low-dose rate (LDR) brachytherapy (dose rate $0.4-2 \mathrm{~Gy} / \mathrm{h}$ ), producing gamma rays by its radioactive decay and with a half-life of 74.2 days which allowed its reuse, making treatment more economical. ${ }^{53-56}$ In this treatment modality, Iridium-192 seeds sealed with a thick stainless steel capsule and placed in a flexible polyethylene were implanted into the tumoral tissue; more than one seed could be sealed in one tube forming wires that were implanted through the tumor. ${ }^{54,55}$ The total dose administered was calculated by the product of dose rate and time the seed was in place (the longer the time, the higher the total dose). ${ }^{55}$ Therefore, the radioisotope was implanted for the time needed to achieve the prescribed dose. ${ }^{54}$ This treatment was advantageous in comparison to external RT because higher doses of radiation could be achieved within the tumor without minimal effects to the non-neoplastic surrounding tissues, as the dose rate exponentially decreased with distance from the source. ${ }^{49,55,57}$ Secondary effects within the treated area with LDR brachytherapy were minimal (dermatitis sunburn-like and loss of pigmentation, mainly) and occurred during the first weeks after treatment. ${ }^{53}$ Due to the radioactive hazard when performing Iridium-192 LDR brachytherapy, radioprotection should not be neglected. The therapy room should be duly equipped and constructed according to legislation; to minimize direct contact with the 
radioactive source the manipulator should use adequate clamps and all the personal involved should use a radiation monitoring dosimeter; the animals should ideally stay in a separate room with leaded walls during the treatment time. ${ }^{53}$

Since 2014, in France, it is impossible to use LDR brachytherapy with Iridium-192 wires due to the end of its commercialization, and so after-loading machines (curietherapy systems) are the alternative, offering two treatment possibilities based on the dose rate: pulsed-dose rate (PDR) and high-dose rate (HDR). ${ }^{58-61}$ To keep performing interstitial brachytherapy, the PDR was the only option, but in the case of skin and even more the nasal planum, the thickness is not enough to implantation, and so HDR brachytherapy was developed to irradiate superficial lesions in a fast treatment modality (dose rate over $12 \mathrm{~Gy} / \mathrm{h}$ ). ${ }^{56,58}$

In HDR brachytherapy vectors are responsible for delivering a radioisotope, from a remote radioisotope delivery unit computer-controlled, directly to the neoplastic tissue, which allows a sparing effect on the surrounding normal tissues and none dissipation of radiation to the room and, mostly, to the technicians, although a proper shielded room is not dismissed. ${ }^{61}$ To perform this superficial irradiation, molds or applicators could be specifically made, in wax for example, to help positioning the vectors. ${ }^{58}$

In contrast to LDR, HDR brachytherapy have more severe side effects which is not surprising due to the elevated doses of radiation: local irritation, ulcers, osteonecrosis, mucositis radiation related, and possible irreversible depigmentation, sneezing and swelling.

HDR brachytherapy is a fast therapeutic modality and can be completed in a period less than a week with an overall treatment time very short.

The literature on this topic is very poor, even more when it comes to the use of HDR brachytherapy in feline SCC of the nasal planum, without any published studies.

\subsubsection{Clinical trials of $\mathrm{RT}$ in feline $\mathrm{SCC}$ of the nasal planum}

Radiation therapy has been used over the past years in cats with the purpose of treating SCC of the nasal planum. So far, to the author's knowledge, there are few publications of clinical trials studying the clinical outcome and possible prognostic factors associated with the use of RT in the treatment of this tumor. Table 1 summarizes the publications reviewed. 
Table 1 - Clinical trials of RT in SCC of the nasal planum.

\begin{tabular}{|c|c|c|c|c|}
\hline $\begin{array}{l}\text { PATIENTS, } \\
\text { TUMOR TYPE }\end{array}$ & RADIATION PROTOCOL & Clinical RESPONSE & ADVERSE EFFECTS & CONCLUSIONS / COMMENTS \\
\hline \multirow{2}{*}{$\begin{array}{c}88 \text { cats, nasal } \\
\text { planum SCC } \\
(\text { Carlisle } \text { et al. } \\
\quad 1982)^{29}\end{array}$} & $\begin{array}{l}\text { Photon beam (x-rays): monthly doses } \\
\text { of } 2000 \mathrm{rad}(n=62) .\end{array}$ & $\begin{array}{l}\text { - } 2 \text {-y total remission } 37 \% \\
\text { - DFI } 13 \text { m }(390 \mathrm{~d}) \\
\text { - } 63 \% \text { recurred after CR } \\
\text { - NR } 11 \% \\
\end{array}$ & \multirow{2}{*}{$\begin{array}{l}\text { AR: grade } 1 \text { solved in } \\
\text { the first few weeks }\end{array}$} & \multirow{2}{*}{$\begin{array}{l}\text { - Mean age } 8.5 \text { y }(1 \text { to } 17 \mathrm{y}) \\
\text { - Therapy with } 3 \text { doses per week with more satisfactory results } \\
\text { - RT is efficient for early stages SCC of the nasal planum } \\
\text { - T3 tumors with a lower overall response; better response to } \\
\text { monthly doses }\end{array}$} \\
\hline & $\begin{array}{l}\text { Photon beam (x-rays): three } 1000 \mathrm{rad} \\
\text { doses in } 1 \text { week, total dose } 3000 \mathrm{rad} \\
(\mathrm{n}=26) .\end{array}$ & $\begin{array}{l}\text { - 2-y total remission } 57 \% \\
\text { - DFI } 17 \text { m }(510 \mathrm{~d}) \\
\text { - } 35 \% \text { recurred after CR } \\
\text { - NR } 8 \%\end{array}$ & & \\
\hline $\begin{array}{c}90 \text { cats, nasal } \\
\text { planum SCC } \\
\text { (Théon et al., } \\
1995)^{7}\end{array}$ & $\begin{array}{l}\text { Photon beam (x-rays): ten fractions of } \\
4 \text { Gy (MWF schedule) over } 3.5 \text { weeks, } \\
\text { total dose } 40 \text { Gy. }\end{array}$ & $\begin{array}{l}- \text { Median PFS } 16.5 \mathrm{~m}(495 \mathrm{~d}) \text {; } \\
\text { - } 1 \text { - and } 5 \text {-y PFS rates } 60.1 \% \\
\text { and } 10.3 \% \\
\text { - Mean PFS T1 } 53.2 \mathrm{~m}(1596 \\
\text { d), T3 } 18.8 \mathrm{~m}(564 \mathrm{~d}) \text { and T4 } \\
15.3 \mathrm{~m}(459 \mathrm{~d})\end{array}$ & $\begin{array}{l}\text { - AR: grade } 1 \text { with } \\
\text { reversible alopecia in } \\
\text { all cats }\end{array}$ & $\begin{array}{l}\text { - Mean age } 11.1 \text { y }(3 \text { to } 20 \mathrm{y}) \\
\text { - Tumor stage ( } \mathrm{p}=0.014) \text { and } \mathrm{PF}(\mathrm{p}=0.016) \text { are prognostic variables } \\
\text { - T1 tumors have better prognosis than } \mathrm{T} 3(\mathrm{p}=0.005) \text { and } \mathrm{T} 4 \\
(\mathrm{p}=0.006) \\
\text { - RT is an efficient option to manage local SCC ( } 11 \text { cure rate } 56 \%) \\
\text { - RT results of FIV-infected cats didn't significantly differ from the } \\
\text { noninfected }\end{array}$ \\
\hline $\begin{array}{l}15 \text { cats, nasal } \\
\text { planum SCC } \\
\text { (Fidel } \text { et al. } \\
\quad 2001)^{62}\end{array}$ & $\begin{array}{l}\text { Accelerated hypofractionated proton } \\
\text { beam: two fractions per day, on } 4 \\
\text { consecutive days (TWTF), total dose: } \\
40.6 \text { CGE for } 9 \text { cats, } 42.4 \text { CGE for } 3 \\
\text { cats and } 44.8 \text { CGE for } 3 \text { cats. }\end{array}$ & $\begin{array}{l}- \text { OCB } 93 \%(\text { CR } 60 \%, \text { PR } \\
33 \%, \text { NR } 6.6 \%) \\
\text { - Median OS } 946 \mathrm{~d} \\
\text { - Median PFS } 440 \mathrm{~d} \\
\text { - } 1 \text {-y PFS rate } 53 \%\end{array}$ & $\begin{array}{l}\text { - AR: grade } 1 \text { or } 2 \\
(\mathrm{n}=12) \text { and grade } 3 \\
(\mathrm{n}=2) \text {, with eversible } \\
\text { alopecia in all cats } \\
\text { - LR: grade } 1(\mathrm{n}=13)\end{array}$ & $\begin{array}{l}\text { - Mean age } 11.6 \text { y (median } 12 \text { y) } \\
\text { - Large number of deaths non-tumor related } \\
\text { - Less late morbidity in the high dose group } \\
\text { - Only } 1 / 9 \text { cats with CR recurred } \\
\text { - The authors supported the idea of nasal planum SCC being a fast- } \\
\text { growing tumor based on their rapid response or failure }\end{array}$ \\
\hline $\begin{array}{l}6 \text { cats, nasal } \\
\text { planum SCC } \\
\text { (de Vos et al., } \\
2004)^{39}\end{array}$ & $\begin{array}{l}\text { Photon beam (x-rays): three fractions } \\
\text { of } 4 \text { Gy per week (MWF schedule) } \\
\text { over } 4 \text { weeks, total dose } 48 \text { Gy; and } \\
\text { Carboplatin once a week over the } 4- \\
\text { week period, } 30 \text { min before RT. } \\
\end{array}$ & $\begin{array}{l}\text { - CR } 100 \% \\
\text { - Median follow-up time: } \\
268 \mathrm{~d}\end{array}$ & $\begin{array}{l}\text { AR: grade } 1 \text { (self- } \\
\text { limiting periods of } \\
\text { sneezing) }\end{array}$ & $\begin{array}{l}\text { - Mean age } 14.8 \mathrm{y} \text { (median } 13.5 \mathrm{y} \text { ) } \\
\text { - Combination of RT and intratumoral carboplatin considered } \\
\text { useful in the treatment of advanced stage SCC of the nasal planum, } \\
\text { with a promising clinical response. }\end{array}$ \\
\hline $\begin{array}{l}17 \text { cats, nasal } \\
\text { and periocular } \\
\text { SCC }^{\text {a }}(\text { Melzer } \\
\text { et al. }, 2006)^{27}\end{array}$ & $\begin{array}{l}\text { Accelerated hypofractionated } \\
\text { electron beam: ten fractions of } 4.8 \mathrm{~Gy} \\
\text { on } 5 \text { consecutive days, total dose } 48 \\
\text { Gy. }\end{array}$ & $\begin{array}{l}- \text { CR } 94 \%(16 / 17) \\
\text { - Median DFI } 414 \text { d } \\
\text { - Median DFI for Ki67 score: } \\
21 \text { d score } 1,487 \text { d score } 2 \\
1129 \text { d score } 3 \\
\text { - } 1-\text { and } 2-y \text { DFI } 66 \% \text { and } \\
40 \%\end{array}$ & $\begin{array}{l}-\mathrm{AR}: \text { grades } 1-3 \\
-\mathrm{LR} \text { : grades } 1-2\end{array}$ & $\begin{array}{l}\text { - Mean age } 11.1 \mathrm{y} \text { (median } 11.2 \mathrm{y} \text { ) } \\
\text { - Higher stage of tumor correlates with shorter DFI ( } \mathrm{p}=0.056) \text {. } \\
\text { - Cats with high Ki67 scores with longer tumor control and so the } \\
\text { protocol is appropriate to treat fast-growing tumors } \\
\text { - Ki67 is a positive prognostic factor for treatment response }\end{array}$ \\
\hline
\end{tabular}


Table 1 - continuation

\begin{tabular}{|c|c|c|c|c|}
\hline $\begin{array}{l}15 \text { cats, nasal } \\
\text { planum SCC } \\
(\text { Goodfellow et } \\
\text { al., 2006) })^{26}\end{array}$ & $\begin{array}{l}\text { Strontium-90 plesiotherapy: five } \\
\text { fractions of } 10 \text { Gy delivered at a depth } \\
\text { of } 2 \mathrm{~mm} \text { over a } 10 \text {-day period (MWF } \\
\text { schedule), total dose } 50 \text { Gy. }\end{array}$ & $\begin{array}{l}\text { - OCB } 100 \%(\text { CR } 87 \%, \text { PR } \\
13 \%) \\
\text { - Median OS } 780 \text { d } \\
\text { - } 1-, 2-\text { and } 5-y \text { OS rates } 77 \%, \\
51 \% \text { and } 15 \% \\
\text { - Median DFI } 652 \text { d } \\
\end{array}$ & $\begin{array}{l}\text { AR: grade } 1 \text { and long } \\
\text { term alopecia }\end{array}$ & $\begin{array}{l}\text { - Mean and median age } 12 \mathrm{y} \\
\text { - All cats with CR remained disease-free for the duration of the } \\
\text { study } \\
\text { - In the authors opinion Sr-90 therapy is simple, safe, with good } \\
\text { outcome and cosmetic results, well tolerated. }\end{array}$ \\
\hline $\begin{array}{c}49 \text { cats, nasal } \\
\text { planum SCC } \\
(\text { Hammond et } \\
\text { al., 2007) })^{12}\end{array}$ & $\begin{array}{l}\text { Strontium-90 plesiotherapy: single } \\
\text { high-dose fraction of one or multiple } \\
\text { overlapping site applications of a Sr-90 } \\
\text { ophthalmic applicator (median dose } \\
128 \mathrm{~Gy}, 1 \text { to } 6 \text { applications). }\end{array}$ & $\begin{array}{l}\cdot \text { OCB } 98 \%(C R 88 \%, \text { PR } \\
10 \%) \\
\cdot \text { Median OS >8 y (>2920 d) } \\
\cdot 1-, 2-\text { and 5-y OS rates } 98 \% \text {, } \\
92 \% \text { and } 55 \% \\
\text { - Median PFS } 4.7 \text { y }(1715 \text { d) }\end{array}$ & $\begin{array}{l}\text { AR: } 1 \text { solved in the } \\
\text { first few weeks }\end{array}$ & $\begin{array}{l}\text { - Mean and median age } 12 \text { y }(4 \text { to } 16 \text { y) } \\
\text { - All SCC in situ had CR without recurrence } \\
\text { - Cats with CR had a longer OS ( }<<0.001) \text { than cats with PR } \\
\text { - Advantageous when compared to surgery or external beam RT }\end{array}$ \\
\hline $\begin{array}{c}3 \text { cats, nasal } \\
\text { planum SCC } \\
(\text { Trivillin } \text { et al., } \\
2008)^{63}\end{array}$ & $\begin{array}{l}\text { BNCT: administration of } 300 \mathrm{mg} \mathrm{kg}^{-1} \\
\text { of }{ }^{10} \mathrm{BPA} \text { IV and irradiation with } \\
\text { thermalized epithermal neutron beam } \\
3 \mathrm{~h} \text { after (average flux } 3.4 \pm 0.3 \times 10^{8} \\
\text { neutrons } \mathrm{cm}^{-2} \mathrm{~s}^{-1} \text { over } 40 \mathrm{~min} \text {, fluence } \\
\text { oh thermal neutrons } 8.2 \times 10^{11} \text { neutrons } \\
\mathrm{cm}^{-2} \text { ). }\end{array}$ & PR in all cats & $\begin{array}{l}\text { AR: grade } 1 \text { for skin } \\
\text { and grade } 2 \text { for } \\
\text { mucous membrane }\end{array}$ & $\begin{array}{l}\text { - Treatment improved cats' clinical condition } \\
\text { - BPA-BNCT can induce partial tumor control, reduction in tumor } \\
\text { volume and radiation-induced tumor cell damage non-affecting } \\
\text { normal tissue. } \\
\text { - BPA-BNCT may not be adequate for smaller and early stage SCC }\end{array}$ \\
\hline $\begin{array}{l}15 \text { cats, facial } \\
\text { SCC (Cunha et } \\
\text { al. }, 2010)^{15}\end{array}$ & $\begin{array}{l}\text { Hypofractionated electron beam: } \\
\text { four fractions of } 7.6 \text { or } 10 \text { Gy each, } \\
\text { with } 1 \text { week interval, total dose } 30.4 \text { or } \\
40 \mathrm{~Gy} \text {. }\end{array}$ & $\begin{array}{l}\text { SCC nasal planum: } 8 / 15 \text { cats, } \\
\text { with CR } 50 \%(n=4) \text { and NR } \\
50 \%(n=4)^{\mathbf{b}} \\
\text { For all } 15 \text { cats: mean OS } 224 \\
\text { d; mean DFI } 271 \text { d }\end{array}$ & $\begin{array}{l}\text { AR: grade } 1(\mathrm{n}=1) \\
\text { and grade } 3(\mathrm{n}=1) \\
\text { resolved with } \\
\text { supportive treatment. }\end{array}$ & $\begin{array}{l}\text { - Mean age } 11 \text { y ( } 7 \text { to } 17 \mathrm{y}) \\
\text { - Response rates were lower than the previous published, possibly } \\
\text { because of the advanced stage lesions ( } 60 \% \text { were } \mathrm{T} 3 \text { and T4) } \\
\text { - The authors concluded that modifications to the protocol are } \\
\text { needed to improve treatment responses }\end{array}$ \\
\hline
\end{tabular}

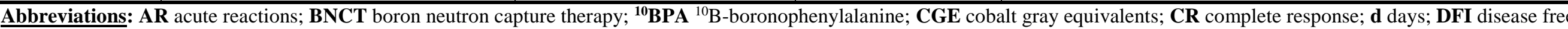

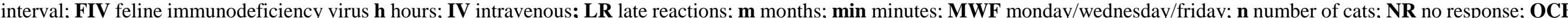

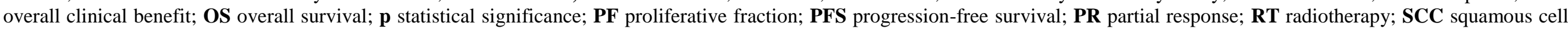

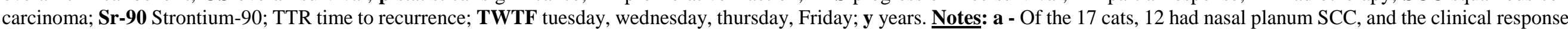

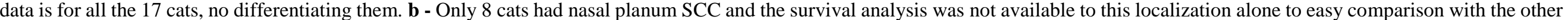
studies. 
In 1982, Carlisle et al. ${ }^{29}$ studied the response of a population of 88 cats with SCC of the nose to RT with X-rays in two regimens: a monthly irradiation of 2000 rad dose each time with the total dose varying with the healing state, and a one week treatment of 3 irradiations of 1000 $\mathrm{rad}$, with a total dose of $3000 \mathrm{rad}$. Total remission was achieved with both protocols in more than $85 \%$ of the cats despite the later recurrence of some of them. RT with 3 doses in one week had the best results with $57 \%$ of the cats in total remission for 2 years, compared with the $37 \%$ achieved with the other regimen, supporting the advantages of dose fractionation. Tumors staged $\mathrm{T} 1$ showed better responses than $\mathrm{T} 2$ and $\mathrm{T} 3$, as they are smaller in size and superficial; T3 lesions showed a lower overall response (marked initially but not maintained, remaining static or growing despite further irradiation), but the response was better with monthly doses and so it was suggested that this regimen should be considered.

A study using Strontium-90 plesiotherapy for early stages of SCC of the nasal planum was presented as an abstract at the annual conference of the Veterinary Cancer Society in 1993 by Vechten et $\boldsymbol{a l} .{ }^{52}$. Treatment was done with using an applicator with an active diameter of 8.7 $\mathrm{mm}$. The dose used was $200 \mathrm{~Gy}$ using one, two or three fields. Mean age of the 25 cats was 10.6 years (range 4 - 19 years). Mean PFS was 34 months (1020 days), 1 and 3-year PFS rates were $89 \%$ and $82 \%$, respectively, and recurrence was only observed in three cats. Acute toxicity was minimal and there were no late effects.

In 1995 Théon et al. ${ }^{7}$ wanted to analyze which prognostic factors could have effect on the response to RT with x-rays fractionated protocol, and the effectiveness of this protocol. PFS was analyzed considering the color of the fur, the presence of multiple facial lesions, the histologic grade, the tumor proliferative fraction (PF) and the stage according to the TNM classification. Tumor stage $(\mathrm{p}=0.014)$ was found to be a prognostic variable. T1 tumors have better prognosis than $\mathrm{T} 3(\mathrm{p}=0.005)$ and $\mathrm{T} 4(\mathrm{p}=0.006)$, with a mean PFS for $\mathrm{T} 1, \mathrm{~T} 3$ and T4 tumors of 53.2 months (1596 days), 18.8 months (564 days) and 15.3 months (459 days), respectively. T1 tumors had a 5-year PFS rate of 56\%, compared to the $10.6 \%$ of T2 tumors. Tumor PF ( $\mathrm{p}=0.016)$ was also found to be a prognostic variable for tumor response. Whereas stage related to the total dose of radiation, PF related to total treatment time, and both could be managed with the appropriate fractionation regimen, to be possible to increase the irradiated dose avoiding radiation effects. In this study 11/90 cats were FIV positive but RT results of the infected cats didn't significantly differ from the non-infected, so the authors encourage that FIV infection status shouldn't be a decision variable regarding the treatment. The only concern 
following RT in these cats was related with the observed higher risk of chronic ulceration of upper lip $(\mathrm{p}=0.001)$.

In 2001, Fidel et $\boldsymbol{a l}$. $^{62}$ treated 15 cats with an accelerated protocol of proton radiation which allowed irradiation of a confined area with high doses radiation. Total doses were increased when the adverse effects were considered minimal, and they concluded that the used doses could still be escalated as there was no acute nor late reactions for none of the cats. In this study, cats that poorly responded to RT had a fast tumor progression (30, 38 and 56 days), and that is why the authors supported the idea of nasal planum SCC being a fast-growing tumor as they quickly respond or fail.

Three years later, another study was publish by de Vos et $\boldsymbol{a l} .{ }^{39}$, combining superficial x-rays RT with intralesional administration of carboplatin, with the intent of potentiating the effect of RT in a population of 6 cats. All the cases achieved CR. Only one cat was euthanized following the evolution of his rhinitis into a therapy-resistant disease and the others remained in complete remission at the end of follow-up. Median follow-up time was 268 days and at the time, time to progression (TTP), TTR and overall survival (OS) were not met. Despite this, the combined protocol showed promising clinical responses considering the advanced stages of the cats' tumors ( $\mathrm{n}=1 \mathrm{~T} 2, \mathrm{n}=2 \mathrm{~T} 3$ and $\mathrm{n}=3 \mathrm{~T} 4)$.

First in 2006 Melzer et al. ${ }^{27}$ tested the response to electron beam RT of nasal and periocular SCC, according to their proliferative activity, using Ki67 immunohistochemistry as proliferation index. They hypothesized that tumors with higher proliferative activity would have better responses and tumor control. Although the data is relative to cats with nasal and periocular SCC, the majority was nasal (12/17) and the results confirm the hypothesis: median DFI for Ki67 score 1 was 21 days, for score 2 it was 487 days and for score 3 it was 1129 days. So, this protocol was considered appropriate to treat fast-growing tumors, with $94 \% \mathrm{CR}$. Tumor control was similar to the previous published studies: median disease free interval (DFI) of 440 days, compared to 390 and 510 days (13 and 17 months $)^{29}, 495$ days (16.5 months $)^{7}$ and 440 days $^{62}$. It was also reported that higher stage of tumor correlates with shorter DFI $(\mathrm{P}=0.056)$.

In the same year (2006) was published a retrospective study with 15 cats treated with Sr-90 plesiotherapy by Goodfellow $\boldsymbol{e t}$ al. ${ }^{26}$. All cats had an overall clinical benefit with $87 \%(\mathrm{n}=13)$ achieving CR and 13\% ( $\mathrm{n}=2)$ achieving PR, and only two cats needed a second RT cycle following a PR, achieving after that a CR. All cats with CR remained disease-free for the duration of the study, and the median DFI was 652 days (range 134 - 2043). Median OS was 780 days. In the authors opinion Sr-90 plesiotherapy is an excellent alternative to orthovoltage 
radiation in the management of superficial SCC since it allows a much precise irradiation of the target area, with high radiation doses at the surface of the skin but sparing the underlying nonneoplastic tissues.

Hammond et al $^{12}$ published in 2007 a retrospective study in order to analyze the outcome of 49 cats following RT with a single fraction of Strontium-90. All the 49 cats were diagnosed with superficial SCC: 35 presented a SCC and 14 has a SCC in situ. CR was achieved by $88 \%$ $(\mathrm{n}=43)$ and PR by $10 \%(\mathrm{n}=5)$ while $2 \%(\mathrm{n}=1)$ did not respond to treatment. CR was achieved by $100 \%$ of the cats with SCC in situ. It was observed that cats with CR had a longer OS (3076 days) than cats with PR (581 days) ( $\mathrm{p}<0.001)$. Median follow-up time was 1018 days (166 to 4168 days) and recurrence occurred in 10/35 cats. OS and times of tumor control were larger than those previously published. Median OS was 3076 days and 1- and 5-years OS rates were $98 \%$ and $55 \%$, compared to $77 \%$ and $15 \%$, respectively, reported by Goodfellow et al. ${ }^{26}$. The same is applied to times of tumor control: median PFS was 1710 days, compared with the median DFI of 652 days reported by Goodfellow et $a l .{ }^{26}$. Based on these results this treatment protocol was considered advantageous to manage small and superficial SCC when compared to surgery or external beam RT, also due to short treatment times, submission to a single anesthesia event and lower costs.

The first boron neutron capture therapy (BNCT) study in spontaneous feline tumors was published in 2004 by Rao et $\mathbf{a l}$. $^{64}$. It was assessed the possibility of treating SCC in cats considered to be terminal due to their tumor with a low dose BPA-BNCT (Boronophenylalanine mediated BNCT) - flux of thermal neutrons was $3 \times 10^{8}$ neutrons $/ \mathrm{cm}^{2}$ s over $10 \mathrm{~min}$, resulting in a fluence of thermal neutrons of $1.8 \times 10^{11}$ neutrons $/ \mathrm{cm}^{2}$. Of the 3 cats included in the study, 2 had nasal SCC, and 12 and 13 years old. Both cats had their tumors partially controlled after treatment, with a clinical condition improvement. After the treatment, one was euthanized at 2.5 months and the other at 9.5 months (but this one was submitted to a new BPA-BNCT 7.5 months after the first treatment). Despite the low dose used, therapeutic effect was achieved and no radiotoxic effects were registered. In the sequence of this publication, Trivillin et al. ${ }^{63}$, in 2008, published another study with BNCT after the promising results of their first. This one included 3 cats with nasal planum SCC and the irradiations lasted $40 \mathrm{~min}$, resulting in a larger fluence of thermal neutrons. In all cats was observed a PR to treatment and tumor restarted growing 1 month (30 days), 5 months (150 days) and 4.5 months (135 days) after the treatment. And although the cats were euthanized 2 months (65 days), 5 months (150 days) and 7.5 months (225 days) after BPA-BNCT, they showed an improvement clinical condition after an important 
reduction in tumor volume. According to the ${ }^{10} \mathrm{BPA}$ biodistribution studies made in this publication, boron concentration was greater the larger the tumor was, and so BPA-BNCT may not be the ideal approach for smaller and early stage SCC.

In 2010, a study published by Cunha et al. ${ }^{15}$ used an hypofractionated protocol in the treatment of cutaneous SCC. Of the total 15 cats, 8 (32\%) had nasal planum SCC. The pinna was the most affected site (33\%) and nasal planum was next; eyelid and tempora were also affected (16\% and 12\%). Survival analysis was made to all the cats hampering comparisons with the previous publications. Mean OS was 224 days. The tumors that achieved a CR showed signs of recurrence with a mean time of 271 days (64 - 720), with a median follow-up of 5 months. Of the 8 cats, $50 \%(n=4)$ achieved CR (2/4 were T3 lesions and 2/4 were T4 lesions) and $50 \%(\mathrm{n}=4)$ did not respond to the treatment (1/4 was a T2 lesion and 3/4 were T4 lesions).

To the author's knowledge none of the published studies on radiotherapy treatment for feline SCC of the nasal planum are on high-dose rate brachytherapy. Therefore, the next part of this work is a preliminary retrospective study and the first clinical investigation to assess the outcome of cats with SCC of the nasal planum treated with HDR brachytherapy. 


\section{OBJECTIVES}

The main purpose of this retrospective study was to describe and statistically analyze the effect of population's and tumor's variables on progression-free survival and overall survival in a population of cats with squamous cell carcinoma of the nasal planum, treated with highdose rate brachytherapy. Therefore, the objectives of the present study were:

1 - Elaborate retrospectively a data base with the animals;

2 - Statistically evaluate the collected data, including survival analysis by Kaplan-Meier curves;

3 -Compare the obtained results with the data from the bibliography. 


\section{MATERIALS AND METHODS}

\section{Case selection}

It was performed a retrospective review of clinical records of 58 cats with SCC of the nasal planum treated with high dose rate (HDR) brachytherapy at Clinique Vétérinaire Alliance, in Bordeaux, France, during a 6-year period from 1 June 2010 to 31 July 2016.

\section{Data acquisition}

Data collected from clinical records included: gender, neuter status, breed, age when attended the reference veterinary, number of lesions, localization and size of the tumor, extension to the hairy skin and upper lip, ulceration, lymph node involvement, lung metastases, any previous treatment, tumor response to HDR brachytherapy, recurrence and overall survival. All the variables above, except the last two, were assessed when cats attended the reference consultation and before the HDR brachytherapy treatment.

In relation to the number of lesions two categories were considered: a single lesion or multiple lesions; in case of multiple lesions, the one with the largest diameter was considered. Regarding the localization of the tumor, based on the data from clinical histories, 6 locals were considered: nasal cavity when the tumor invaded the nasal cavity, the nose tip uniquely, dorsal if it was in the dorsal side of the nasal planum, rostral if it was in the rostral side of the nasal planum, nostril wing when the wing of the nostril was affected, and a combination when the lesion affected two or more of the previous ones (Figure 3). The size of the tumor was considered the largest diameter of the visible lesion, and for the purpose of the study, tumors were categorized into two groups: one group with tumors equal or smaller than $2 \mathrm{~cm}$ and the other group with tumors larger than $2 \mathrm{~cm}$ (adaptation of the WHO staging system ${ }^{24}$ ).

Regional lymph node involvement was assessed by cytologic analysis of mandibular lymph nodes. Thoracic radiographs or CT scans were performed to assess lung metastasis. Clinical staging evaluation was assessed using the WHO recommendations ${ }^{24}$. 

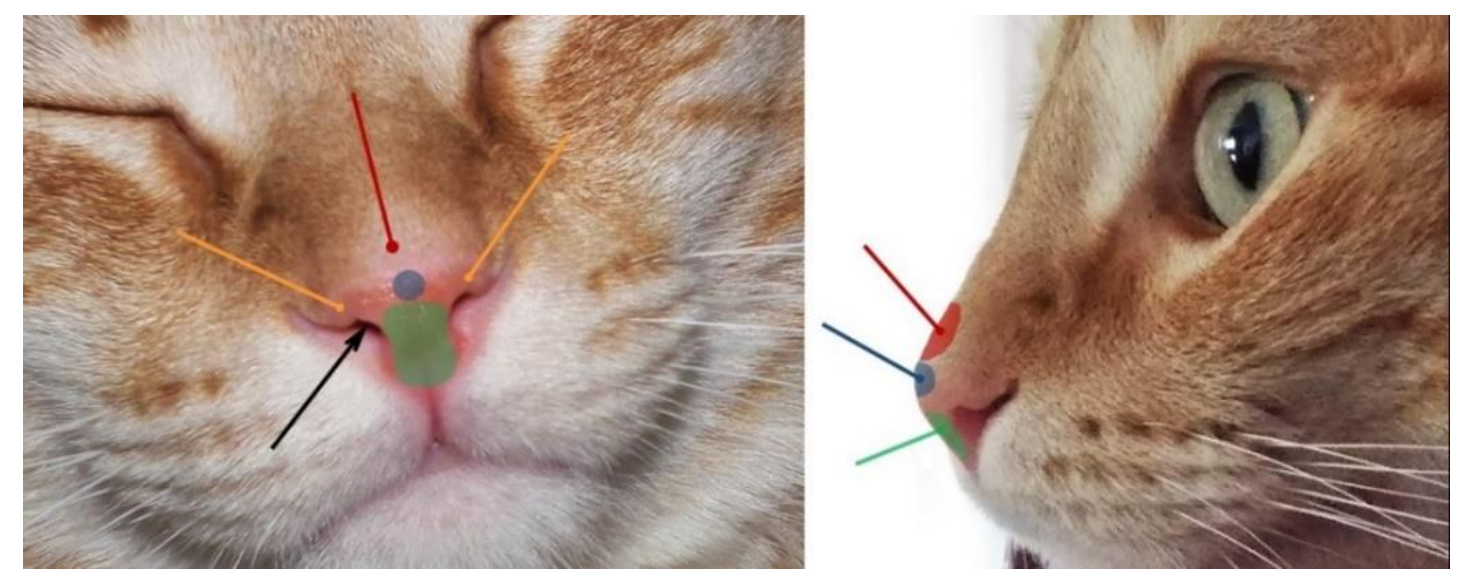

Figure 3 - Considered anatomical localizations of SCC of the nasal planum of the cats of the study. Black arrow - nasal cavity; blue shadow and point - nose tip; red shadow and point - dorsal face; green shadow and point - rostral face; orange point - nostril wing.

\section{Assessment of response}

The treatment protocol used for all the cats was 4 to 5 fractions of 6 Gy for a period of 3 to 4 days.

Tumor response to brachytherapy was determined visually after the end of treatment. It was categorized as complete response (CR) when the measurable lesion completely disappeared and the skin re-epithelized sanely, partial response (PR) when reduction in tumor size was greater than $50 \%$ but with persistence of a small lesion, and progressive disease (PD) when there was an aggravation of the initial lesion with a size increase of more than $25 \%$. $^{12,26}$

Progression-free survival (PFS) was defined as the time from the beginning of treatment until first recurrence or until the end of follow-up if recurrence was not observed. Overall survival (OS) was defined as the length of time cats have lived from the beginning of treatment until death by the tumor or the end of the study.

\section{Statistical analysis}

The statistical software SPSS (Statistical Package for the Social Sciences) version 24.0 was used for statistical analysis. Analysis of variance (ANOVA) was used for continuous variables. For categorical variables was applied the Chi-square test and the Fisher's exact test when appropriated.

Survival curves were generated by the Kaplan-Meier method and the survival rates were compared using the Log Rank test. Considering the median value achieved, the variable age was categorized into two groups for survival analysis (group 1 was composed by cats with an 
age equal or inferior to the median value, and the group 2 by cats with an age superior to the median value). For survival analysis interpretation, two endpoint periods were considered (500 and 1000 days, based on the clinical impact and relevance). These endpoints allowed a more objective comparison between groups. In this work, there were no animals lost for follow-up, therefore censored observations correspond to animals that died from causes other than the neoplastic disease or that remained alive at the end of the study period. ${ }^{65}$

Continuous variables were expressed as means \pm standard deviation. In all statistical comparisons, $\mathrm{p}<0.05$ was accepted as denoting statistically significant differences. 


\section{RESULTS}

\section{Population characteristics}

\subsection{Gender}

Fifty-eight cats were included in this study of which 31 were male (53.4\%) and 27 were female (46.6\%) (Graph 1).

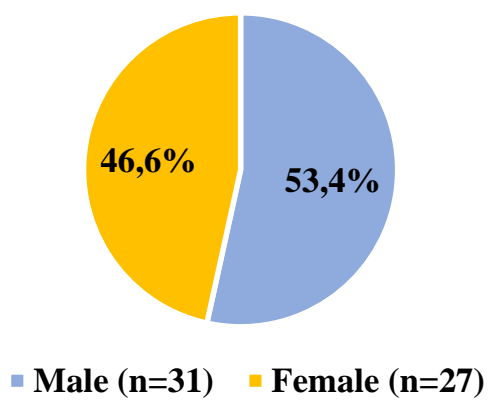

Graph 1 - Distribution of the population $(n=58)$ by gender.

\subsection{Neuter status}

Information about the neuter status was available for 56 cats: 55 cats $(98.2 \%)$ were neutered and only 1 (1.8\%) was intact (Graph 2).

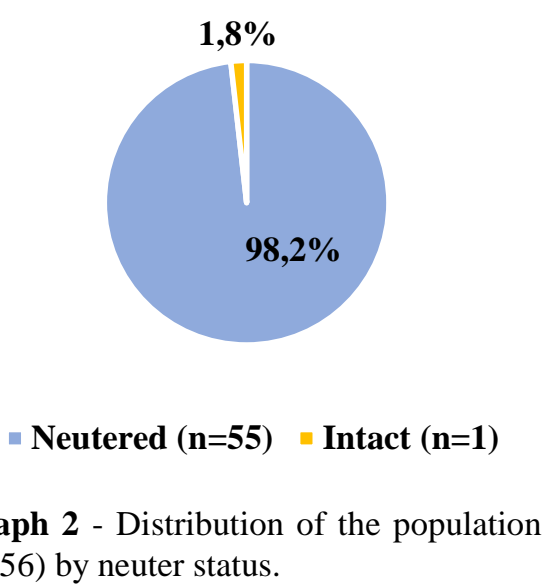

\subsection{Breed}

The majority $(96.6 \%)$ of cats were Common European $(\mathrm{n}=56)$ and the other breeds corresponding to 2 cats (3.4\%) were Turkish and Birman crossed (Graph 3). 


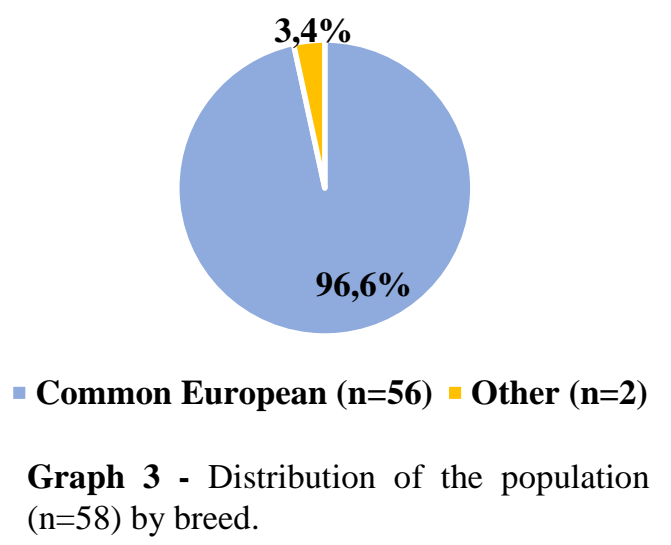

\subsection{Age}

The mean age when the cats attended to the reference appointment was $11.2( \pm 3,231)$ years old, with the minimum and maximum ages of 3 and 17 years old. The mean age was very similar between males (11.2 years) and females (11.3 years). Considering the mean age achieved, this variable was categorized into two groups for survival analysis: the first group was composed by cats with an age equal or inferior to 11 years old $(n=29 / 57 ; 50.9 \%)$, and the second with the cats with an age superior to 11 years old ( $n=28 / 57 ; 49.1 \%)$. The box and whisker plot (Graph 4) gives the spread of the age.

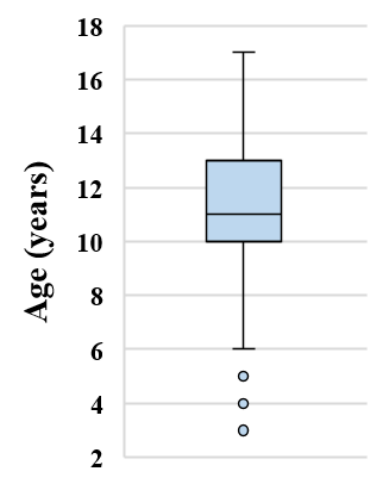

Graph 4 - Box and whisker plot of age. The central line corresponds to the mean age 11 years old.

\section{Tumor characteristics}

\subsection{Number of lesions}

Number of lesions on the nasal planum were divided into single and multiple lesions. Data was available for 57 cats (Graph 5), of which 12 (21.1\%) presented multiple lesions and 45 (78.9\%) had a single lesion. 


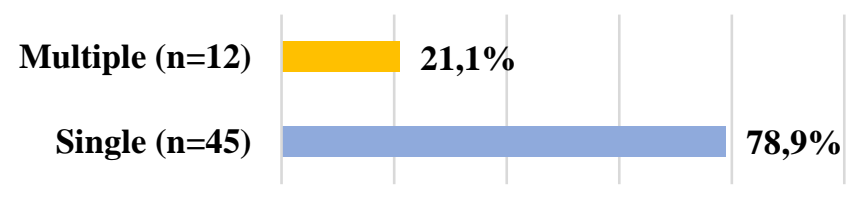

Graph 5 - Distribution of the population $(n=57)$ by number of lesions.

\subsection{Localization of the tumor}

Based on the clinical records, the localization of the tumor on the nasal planum was available for 56 cats: 1 cat $(1.8 \%)$ had the tumor in the nasal cavity, 2 cats $(3.6 \%)$ in the nose tip, 3 cats $(5.4 \%)$ had it in the dorsal face, 4 cats $(7.1 \%)$ in the rostral face, 19 cats $(33.9 \%)$ had the wing of one of both nostrils affected, and 27 cats (48.2\%) had a combination of two or more of the above (Graph 6).

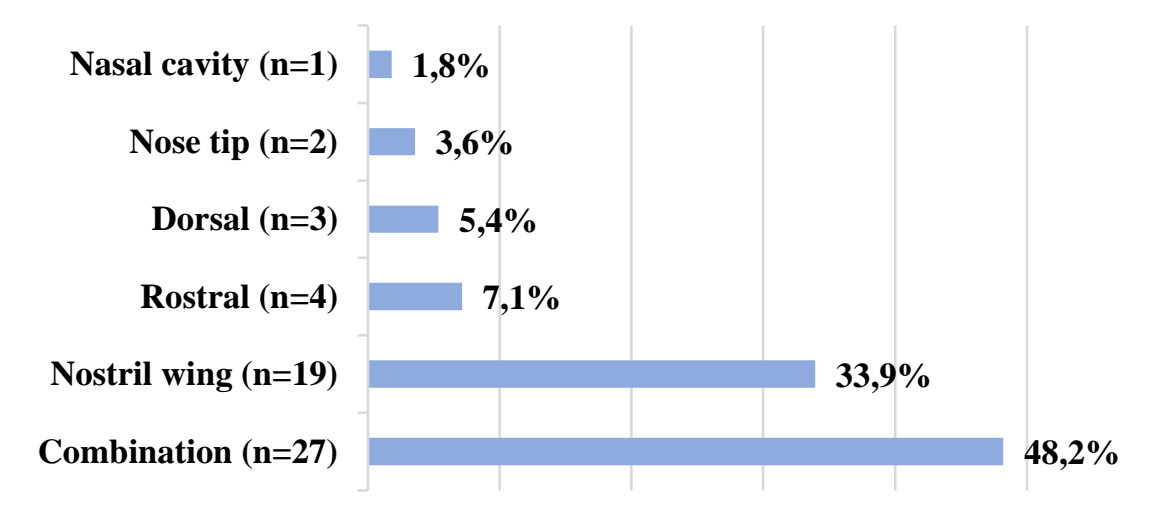

Graph 6 - Distribution of the population $(n=56)$ by localization of the tumor.

\subsection{Affection of surrounded areas}

The extension of the tumor from the nasal planum was observed to the hairy skin and to the upper lip. Extension to the hairy skin was possible to describe in 45 cats: it was absent in $15.6 \%(n=7)$ and detected in $84.4 \%$ of the cats $(n=38)($ Graph 7$)$. Respecting the extension to the upper lip, it was possible to record this event in 52 cats, with $46.2 \%$ cats $(n=24)$ demonstrating upper lip affection and 53.8\% (n=28) with no affection (Graph 8). 


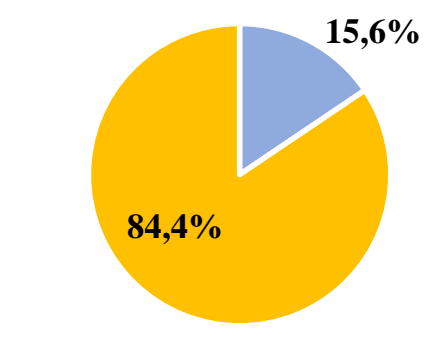

- No hairy skin affected $(n=7)$

- Hairy skin affected $(n=38)$

Graph 7 - Distribution of the population $(\mathrm{n}=45)$ by extension of the tumor to hairy skin.

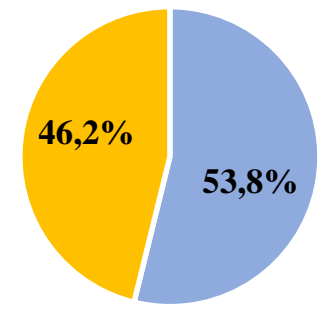

- No upper lip extension (n=28)

- Upper lip extension ( $n=24)$

Graph 8 - Distribution of the population $(\mathrm{n}=52)$ by extension of the tumor to the upper lip.

\subsection{Tumor size}

Regarding the size of the tumor, information was available in 48 cats. In $43.8 \%$ of the cats $(\mathrm{n}=21)$ the tumor was equal or smaller than $2 \mathrm{~cm}$, and in $56.3 \%(\mathrm{n}=27)$ the tumor size was larger than $2 \mathrm{~cm}$ (Graph 9).

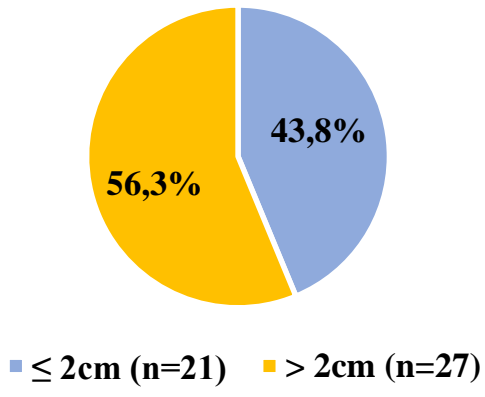

Graph 9 - Distribution of the population $(\mathrm{n}=48)$ by tumor size 


\subsection{Tumor ulceration}

Tumor ulceration was present in $83.6 \%$ of the cats $(n=46)$, and absent in $16.4 \%(n=9)$ (Graph 10).

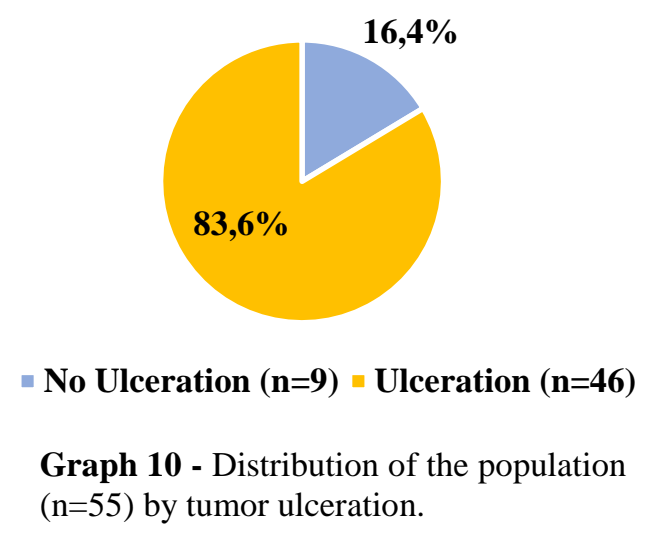

\section{Lymph node involvement}

Records for lymph node involvement by cytology of fine needle aspiration were available for 17 cats and all of them (100\%) demonstrated absence of regional metastases.

\section{Lung metastasis}

Information about lung metastases was possible to assess in 43 cats, revealing absence of lung metastasis in all cases (100\%). Lung metastasis assessment was performed by chest X-rays $(\mathrm{n}=38,88.4 \%)$, CT $\operatorname{scan}(\mathrm{n}=2,4.6 \%)$ and for the remaining $3(7 \%)$ this information was unknown. 


\section{Tumor response to brachytherapy}

According the records, information about previous treatment was available in 55 of the 58 cats. Six cases $(10.9 \%)$ received treatment prior to brachytherapy: 3 of them were treated with surgical resection, 1 with electrochemotherapy, 1 with surgical excision followed by external radiotherapy and electrochemotherapy and chemotherapy, and 1 with electrocauterization. The remaining 49 cases $(89.1 \%$ ) did not receive any type of treatment before HDR brachytherapy.

Following brachytherapy, information about tumor response to treatment was available for 50 cats (Graph 11). After the first brachytherapy treatment, CR was achieved in 36 cats (72\%), $\mathbf{P R}$ in 13 cats (26\%) and $\mathbf{P D}$ in 1 cat (2\%), which corresponds to a response rate and clinical benefit of $98 \%$ (49/50).

According the records for 47 cats, 15 (31.9\%) were submitted to more than one treatment of HDR brachytherapy.

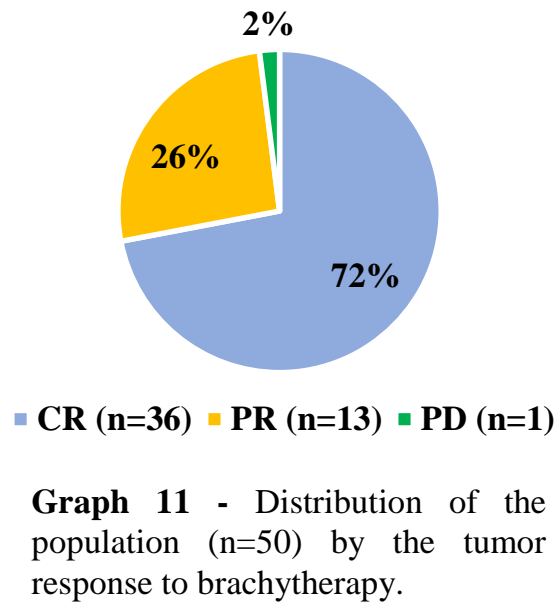

\section{Tumor recurrence}

Tumor recurrence information was available for 43 of the 58 cases. Tumor recurrence was observed in $67.4 \%$ of the cats $(n=29 / 43)$ and the remaining $32.6 \%$ of the cases $(n=14 / 43)$ never recurred (Graph 12). Of the 29 (67.4\%) cases that recurred, 18 cases experienced a previous CR, 10 experienced a previous PR and in 1 case the information about tumor response was unknown.

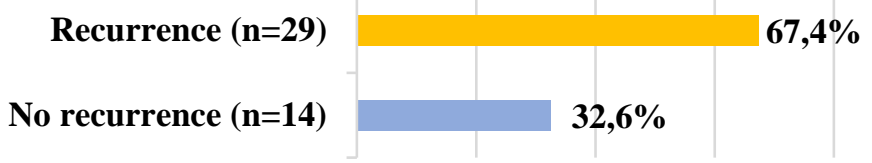

Graph 12 - Distribution of the population $(n=43)$ by recurrence. 


\section{Associations between clinical variables and tumor response to brachytherapy}

The associations between the clinical variables with the tumor response to brachytherapy are summarized in Table 2. Only the size of the tumor revealed a statistically significant association $(p=0.015)$ and seems to have effect on the tumor response.

Table 2 - Associations between clinical variables and tumor response to HDR brachytherapy.

\begin{tabular}{|c|c|c|c|c|c|c|c|}
\hline \multirow[b]{3}{*}{ Variables } & \multicolumn{7}{|c|}{ Tumor response } \\
\hline & \multicolumn{2}{|c|}{ CR } & \multicolumn{2}{|c|}{ PR } & \multicolumn{2}{|c|}{ PD } & \multirow[b]{2}{*}{$\mathbf{p}$} \\
\hline & $\mathbf{N}$ & $\%$ & $\mathbf{n}$ & $\%$ & $\mathbf{n}$ & $\%$ & \\
\hline $\begin{array}{l}\text { Gender } \\
\text { Male } \\
\text { Female }\end{array}$ & $\begin{array}{l}17 \\
19\end{array}$ & $\begin{array}{l}70.8 \\
73.1\end{array}$ & $\begin{array}{l}6 \\
7\end{array}$ & $\begin{array}{c}25 \\
26.9\end{array}$ & $\begin{array}{l}1 \\
0\end{array}$ & $\begin{array}{c}4.2 \\
0\end{array}$ & 0.574 \\
\hline $\begin{array}{l}\text { Neuter Status } \\
\text { Neutered } \\
\text { Intact } \\
\end{array}$ & $\begin{array}{c}34 \\
1 \\
\end{array}$ & $\begin{array}{c}72.3 \\
100 \\
\end{array}$ & $\begin{array}{c}12 \\
0 \\
\end{array}$ & $\begin{array}{c}25.5 \\
0 \\
\end{array}$ & $\begin{array}{l}1 \\
0 \\
\end{array}$ & $\begin{array}{c}2.1 \\
0\end{array}$ & 0.827 \\
\hline $\begin{array}{l}\text { Breed } \\
\text { Common European } \\
\text { Turkish } \\
\text { Birman crossed } \\
\end{array}$ & $\begin{array}{c}35 \\
1 \\
0\end{array}$ & $\begin{array}{c}72.9 \\
100 \\
0 \\
\end{array}$ & $\begin{array}{c}12 \\
0 \\
1 \\
\end{array}$ & $\begin{array}{c}25 \\
0 \\
100 \\
\end{array}$ & $\begin{array}{l}1 \\
0 \\
0\end{array}$ & $\begin{array}{c}2.1 \\
0 \\
0\end{array}$ & 0.515 \\
\hline $\begin{array}{l}\text { Age } \\
\leq 11 \text { years } \\
>11 \text { years }\end{array}$ & $\begin{array}{l}18 \\
18\end{array}$ & $\begin{array}{l}72 \\
75\end{array}$ & $\begin{array}{l}7 \\
6\end{array}$ & $\begin{array}{l}28 \\
25\end{array}$ & $\begin{array}{l}0 \\
0\end{array}$ & $\begin{array}{l}0 \\
0\end{array}$ & 0.812 \\
\hline $\begin{array}{l}\text { Number of Lesions } \\
\text { Single } \\
\text { Multiple }\end{array}$ & $\begin{array}{c}29 \\
7\end{array}$ & $\begin{array}{l}70.7 \\
77.8 \\
\end{array}$ & $\begin{array}{c}11 \\
2\end{array}$ & $\begin{array}{l}26.8 \\
22.2 \\
\end{array}$ & $\begin{array}{l}1 \\
0\end{array}$ & $\begin{array}{c}2.4 \\
0\end{array}$ & 0.848 \\
\hline $\begin{array}{l}\text { Localization } \\
\text { Nostril wing } \\
\text { Rostral } \\
\text { Dorsal } \\
\text { Combination } \\
\text { Nose tip } \\
\text { Nasal cavity }\end{array}$ & $\begin{array}{c}11 \\
3 \\
3 \\
15 \\
2 \\
1\end{array}$ & $\begin{array}{c}73.3 \\
100 \\
100 \\
60 \\
100 \\
100\end{array}$ & $\begin{array}{l}4 \\
0 \\
0 \\
9 \\
0 \\
0\end{array}$ & $\begin{array}{c}26.7 \\
0 \\
0 \\
36 \\
0 \\
0\end{array}$ & $\begin{array}{l}0 \\
0 \\
0 \\
1 \\
0 \\
0\end{array}$ & $\begin{array}{l}0 \\
0 \\
0 \\
4 \\
0 \\
0\end{array}$ & 0.841 \\
\hline $\begin{array}{l}\text { Hairy skin extension } \\
\text { No } \\
\text { Yes }\end{array}$ & $\begin{array}{c}7 \\
19 \\
\end{array}$ & $\begin{array}{c}100 \\
59.4\end{array}$ & $\begin{array}{c}0 \\
12 \\
\end{array}$ & $\begin{array}{c}0 \\
37.5 \\
\end{array}$ & $\begin{array}{l}0 \\
1\end{array}$ & $\begin{array}{c}0 \\
3.1\end{array}$ & 0.119 \\
\hline $\begin{array}{l}\text { Upper lip extension } \\
\text { No } \\
\text { Yes }\end{array}$ & $\begin{array}{l}18 \\
13\end{array}$ & $\begin{array}{l}78.3 \\
59.1\end{array}$ & $\begin{array}{l}5 \\
8\end{array}$ & $\begin{array}{l}21.7 \\
36.4\end{array}$ & $\begin{array}{l}0 \\
1\end{array}$ & $\begin{array}{c}0 \\
4.5\end{array}$ & 0.290 \\
\hline $\begin{array}{l}\text { Tumor size } \\
\leq 2 \mathrm{~cm} \\
>2 \mathrm{~cm}\end{array}$ & $\begin{array}{l}16 \\
13\end{array}$ & $\begin{array}{c}94.1 \\
52\end{array}$ & $\begin{array}{c}1 \\
11\end{array}$ & $\begin{array}{r}5.9 \\
44\end{array}$ & $\begin{array}{l}0 \\
1\end{array}$ & $\begin{array}{l}0 \\
4 \\
\end{array}$ & 0.015 \\
\hline $\begin{array}{l}\text { Ulceration } \\
\text { Absent } \\
\text { Present } \\
\end{array}$ & $\begin{array}{c}5 \\
29 \\
\end{array}$ & $\begin{array}{l}71.4 \\
70.7 \\
\end{array}$ & $\begin{array}{c}2 \\
11 \\
\end{array}$ & $\begin{array}{l}28.6 \\
26.8 \\
\end{array}$ & $\begin{array}{l}0 \\
1 \\
\end{array}$ & $\begin{array}{c}0 \\
2.4\end{array}$ & 0.915 \\
\hline $\begin{array}{l}\text { Lymph node involvement } \\
\text { Absent } \\
\text { Present }\end{array}$ & $\begin{array}{c}15 \\
0\end{array}$ & $\begin{array}{c}88.2 \\
0\end{array}$ & $\begin{array}{l}2 \\
0\end{array}$ & $\begin{array}{c}11.8 \\
0\end{array}$ & $\begin{array}{l}0 \\
0\end{array}$ & $\begin{array}{l}0 \\
0\end{array}$ & $a^{*}$ \\
\hline $\begin{array}{l}\text { Lung metastasis } \\
\text { Absent } \\
\text { Present }\end{array}$ & $\begin{array}{c}31 \\
0\end{array}$ & $\begin{array}{c}79.5 \\
0\end{array}$ & $\begin{array}{l}8 \\
0\end{array}$ & $\begin{array}{c}20.5 \\
0\end{array}$ & $\begin{array}{l}0 \\
0\end{array}$ & $\begin{array}{l}0 \\
0\end{array}$ & $a^{*}$ \\
\hline $\begin{array}{l}\text { Previous treatment } \\
\text { No } \\
\text { Yes }\end{array}$ & $\begin{array}{c}33 \\
3\end{array}$ & $\begin{array}{l}75 \\
75\end{array}$ & $\begin{array}{c}11 \\
1\end{array}$ & $\begin{array}{l}25 \\
25\end{array}$ & $\begin{array}{l}0 \\
0\end{array}$ & $\begin{array}{l}0 \\
0\end{array}$ & 1.000 \\
\hline
\end{tabular}




\section{Associations between clinical variables and tumor recurrence}

The associations between the clinical variables studied with the tumor recurrence are summarized in Table 3. There was no statistically significant association with any of the studied variables.

Table 3 - Associations between clinical variables and tumor recurrence.

\begin{tabular}{|c|c|c|c|c|c|}
\hline \multirow{3}{*}{ Variables } & \multicolumn{5}{|c|}{ Recurrence } \\
\hline & \multicolumn{2}{|c|}{ No } & \multicolumn{2}{|c|}{ Yes } & \multirow{2}{*}{$\mathbf{p}$} \\
\hline & $\mathbf{N}$ & $\%$ & $\mathbf{n}$ & $\%$ & \\
\hline Gender & & & & & \\
\hline Male & 7 & 31.8 & 15 & 68.2 & 0.916 \\
\hline Female & 7 & 33.3 & 14 & 66.7 & \\
\hline \multicolumn{5}{|l|}{ Neuter Status } & \multirow{3}{*}{0.466} \\
\hline Neutered & 14 & 35 & 26 & 65 & \\
\hline Intact & 0 & 0 & 1 & 100 & \\
\hline \multicolumn{5}{|l|}{ Breed } & \multirow{4}{*}{0.277} \\
\hline Common European & 13 & 31.7 & 28 & 68.3 & \\
\hline Turkish & 1 & 100 & 0 & 0 & \\
\hline Birman crossed & 0 & 0 & 1 & 100 & \\
\hline \multicolumn{5}{|l|}{ Age } & \multirow{3}{*}{0.916} \\
\hline$\leq 11$ years & 7 & 33.3 & 14 & 66.7 & \\
\hline$>11$ years & 7 & 31.8 & 15 & 68.2 & \\
\hline \multicolumn{5}{|l|}{ Number of Lesions } & \multirow{3}{*}{0.525} \\
\hline Single & 11 & 30.6 & 25 & 69.4 & \\
\hline Multiple & 3 & 42.9 & 4 & 57.1 & \\
\hline \multicolumn{5}{|l|}{ Localization } & \multirow{7}{*}{0.144} \\
\hline Nostril wing & 3 & 18.8 & 13 & 81.3 & \\
\hline Rostral & 2 & 100 & 0 & 0 & \\
\hline Dorsal & 2 & 66.7 & 1 & 33.3 & \\
\hline Combination & 5 & 27.8 & 13 & 72.2 & \\
\hline Nose tip & 1 & 50 & 1 & 50 & \\
\hline Nasal cavity & 0 & 0 & 1 & 100 & \\
\hline \multicolumn{5}{|l|}{ Hairy skin extension } & \multirow{3}{*}{0.586} \\
\hline No & 1 & 20 & 4 & 80 & \\
\hline Yes & 9 & 32.1 & 19 & 67.9 & \\
\hline \multicolumn{5}{|l|}{ Upper lip extension } & \multirow{3}{*}{1.000} \\
\hline No & 6 & 31.6 & 13 & 68.4 & \\
\hline Yes & 6 & 31.6 & 13 & 68.4 & \\
\hline \multicolumn{5}{|l|}{ Tumor size } & \multirow{3}{*}{0.107} \\
\hline$\leq 2 \mathrm{~cm}$ & 6 & 42.9 & 8 & 57.1 & \\
\hline$>2 \mathrm{~cm}$ & 4 & 18.2 & 18 & 81.8 & \\
\hline \multicolumn{5}{|l|}{ Ulceration } & \multirow{3}{*}{0.671} \\
\hline Absent & 2 & 40 & 3 & 60 & \\
\hline Present & 11 & 30.6 & 25 & 69.4 & \\
\hline Lymph node involvement & & & & & \\
\hline Absent & 7 & 43.8 & 9 & 56.3 & $a^{*}$ \\
\hline Present & 0 & 0 & 0 & 0 & \\
\hline Lung metastasis & & & & & \\
\hline Absent & 11 & 33.3 & 22 & 66.7 & $a^{*}$ \\
\hline Present & 0 & 0 & 0 & 0 & \\
\hline Previous treatment & & & & & \\
\hline No & 13 & 34.2 & 25 & 65.8 & 0.159 \\
\hline Yes & 0 & 0 & 4 & 100 & \\
\hline
\end{tabular}

$a^{*}$ - non-computable (SPSS system information); $n$ - number of cats; $p$ - statistical significance. 


\section{Survival analysis}

Follow-up data was available for 43 of the 58 cases included on the study. At the end of the study, 22 of the 43 cats $(51.2 \%)$ were dead due to tumor related causes and the 21 cats $(48.8 \%)$ were alive $(n=13)$ or dead by other causes $(n=8)$.

For survival analysis, the variables gender, neuter status, breed, age, number of lesions, localization and size of the tumor, extension to the hairy skin / upper lip, ulceration, lymph node involvement, lung metastases, previous treatment and tumor response to brachytherapy were studied. No comparison analysis was done for lymph node involvement neither for lung metastasis because all cases were negative.

\subsection{Progression-free Survival}

Information about PFS time was available for 43 cats. The mean and median times of PFS were 583 days (95\% CI: 406.921 to 759.351 ) and 316 days (95\% CI: 76.642 to 555.358 ), respectively.

Table 4 summarizes the mean and median values of PFS and the cumulative survival at day 500 and 1000. From the analysis of the results it was possible to conclude that a previous treatment $(\mathrm{p}=0.043)$ and the type of response to brachytherapy $(\mathrm{p}=0.038)$ were the only variables that presented a statistical significant association with PFS (Graph 13 and Graph 14).

A previous treatment before HDR brachytherapy was found to have a statistical significant association with the progression-free survival $(\mathrm{p}=0.043)$. Cats that received a previous treatment showed a median PFS of 103 days (95\% CI: 65.760-140.240) and a lower cumulative survival (Graph 13), compared to those that did not receive a previous treatment, which had a median PFS of 403 days (95\% CI: 149.791-656.209). At day 500 all the cats that received a previous treatment were dead, while $40 \%$ of the cats without previous treatment remained free of the disease. This difference was still evident at day 1000 where the percentage of cats free of disease in the group without previous treatment remained above $30 \%(33,3 \%)$.

The tumor response to HDR brachytherapy was found to have a statistical significant association with the progression-free survival $(\mathrm{p}=0.038)$. Cats that presented a PR showed a median PFS of 103 days (95\% CI: 44.737-161.263) and a lower cumulative survival, and the cats that presented a CR showed the highest, with a median PFS of 403 days (95\% CI: 221.039584.961) (Graph 14). At day 500, cats with CR presented a cumulative survival of $42.8 \%$ 
compared to $18.2 \%$ for cats with PR. At day 1000 this difference was not so evident with cats with CR presenting a cumulative survival of $32.1 \%$ against $18,2 \%$ of cats with PR.

Table 4 - Relation between variables and progression-free survival at day 500 and 1000.

\begin{tabular}{|c|c|c|c|c|c|c|}
\hline \multirow[b]{3}{*}{ Variables } & \multicolumn{6}{|c|}{ Progression-free Survival } \\
\hline & \multirow{2}{*}{$\mathbf{n}$} & \multirow{2}{*}{ Mean (d) } & \multirow{2}{*}{ Median (d) } & \multicolumn{2}{|c|}{ Cumulative survival (\%) } & \multirow[b]{2}{*}{$\mathbf{p}$} \\
\hline & & & & $500 \mathrm{~d}$ & $1000 \mathrm{~d}$ & \\
\hline $\begin{array}{l}\text { Gender } \\
\text { Male } \\
\text { Female }\end{array}$ & $\begin{array}{l}22 \\
21 \\
\end{array}$ & $\begin{array}{l}556.5 \\
616.6 \\
\end{array}$ & $\begin{array}{l}269 \\
438 \\
\end{array}$ & $\begin{array}{l}31.6 \\
42.9 \\
\end{array}$ & $\begin{array}{l}31.6 \\
32.1 \\
\end{array}$ & 0.765 \\
\hline $\begin{array}{l}\text { Neuter Status } \\
\text { Neutered } \\
\text { Intact } \\
\end{array}$ & $\begin{array}{c}40 \\
1 \\
\end{array}$ & $\begin{array}{c}617.9 \\
269 \\
\end{array}$ & $\begin{array}{l}403 \\
269 \\
\end{array}$ & $\begin{array}{c}40.7 \\
0\end{array}$ & $\begin{array}{c}34.8 \\
0 \\
\end{array}$ & 0.568 \\
\hline $\begin{array}{l}\text { Breed } \\
\text { Common European } \\
\text { Turkish } \\
\text { Birman crossed } \\
\end{array}$ & $\begin{array}{c}41 \\
1 \\
1 \\
\end{array}$ & $a^{*}$ & $a^{*}$ & $a^{*}$ & $a^{*}$ & $a^{*}$ \\
\hline $\begin{array}{l}\text { Age } \\
\leq 11 \text { years old } \\
>11 \text { years old }\end{array}$ & $\begin{array}{l}21 \\
22\end{array}$ & $\begin{array}{l}603.3 \\
540.4\end{array}$ & $\begin{array}{l}303 \\
316 \\
\end{array}$ & $\begin{array}{l}39.1 \\
35.4\end{array}$ & $\begin{array}{l}39.1 \\
23.6 \\
\end{array}$ & 0.874 \\
\hline $\begin{array}{l}\text { Number of Lesions } \\
\text { Single } \\
\text { Multiple }\end{array}$ & $\begin{array}{c}36 \\
7\end{array}$ & $\begin{array}{c}603.7 \\
194\end{array}$ & $\begin{array}{l}316 \\
160\end{array}$ & $\begin{array}{c}39.3 \\
0\end{array}$ & $\begin{array}{c}33.6 \\
0\end{array}$ & 0.477 \\
\hline $\begin{array}{l}\text { Localization } \\
\text { Nostril wing } \\
\text { Rostral } \\
\text { Dorsal } \\
\text { Combination } \\
\text { Nose tip } \\
\text { Nasal cavity } \\
\end{array}$ & $\begin{array}{c}16 \\
2 \\
3 \\
18 \\
2 \\
1 \\
\end{array}$ & $a^{*}$ & $a^{*}$ & $a^{*}$ & $a^{*}$ & $a^{*}$ \\
\hline $\begin{array}{l}\text { Hairy skin extension } \\
\text { No } \\
\text { Yes } \\
\end{array}$ & $\begin{array}{c}5 \\
28 \\
\end{array}$ & $\begin{array}{l}677.2 \\
580.6 \\
\end{array}$ & $\begin{array}{l}403 \\
303 \\
\end{array}$ & $\begin{array}{c}40 \\
36.1 \\
\end{array}$ & $\begin{array}{c}40 \\
36.1 \\
\end{array}$ & 0.643 \\
\hline $\begin{array}{l}\text { Upper lip extension } \\
\text { No } \\
\text { Yes } \\
\end{array}$ & $\begin{array}{l}19 \\
19 \\
\end{array}$ & $\begin{array}{l}707.5 \\
343.1 \\
\end{array}$ & $\begin{array}{l}438 \\
184 \\
\end{array}$ & $\begin{array}{l}46.8 \\
20.5 \\
\end{array}$ & $\begin{array}{c}46.8 \\
0 \\
\end{array}$ & 0.142 \\
\hline $\begin{array}{l}\text { Tumor size } \\
\leq 2 \mathrm{~cm} \\
>2 \mathrm{~cm} \\
\end{array}$ & $\begin{array}{l}14 \\
22 \\
\end{array}$ & $\begin{array}{c}728 \\
400.7 \\
\end{array}$ & $\begin{array}{c}1032 \\
184 \\
\end{array}$ & $\begin{array}{l}57.1 \\
16.7 \\
\end{array}$ & $\begin{array}{l}57.1 \\
16.7 \\
\end{array}$ & 0.148 \\
\hline $\begin{array}{l}\text { Ulceration } \\
\text { Absent } \\
\text { Present } \\
\end{array}$ & $\begin{array}{c}5 \\
36\end{array}$ & $\begin{array}{l}648.7 \\
545.5\end{array}$ & $\begin{array}{l}955 \\
303\end{array}$ & $\begin{array}{c}60 \\
32.2 \\
\end{array}$ & $\begin{array}{c}30 \\
32.2 \\
\end{array}$ & 0.633 \\
\hline $\begin{array}{l}\text { Lymph node involvement } \\
\text { Absent } \\
\text { Present }\end{array}$ & $\begin{array}{c}16 \\
0 \\
\end{array}$ & $a^{*}$ & $a^{*}$ & $a^{*}$ & $a^{*}$ & $a^{*}$ \\
\hline $\begin{array}{l}\text { Lung metastasis } \\
\text { Absent } \\
\text { Present }\end{array}$ & $\begin{array}{c}33 \\
0\end{array}$ & $a^{*}$ & $a^{*}$ & $a^{*}$ & $a^{*}$ & $a^{*}$ \\
\hline $\begin{array}{l}\text { Previous treatment } \\
\text { No } \\
\text { Yes }\end{array}$ & $\begin{array}{c}38 \\
4\end{array}$ & $\begin{array}{l}580.5 \\
157.5\end{array}$ & $\begin{array}{l}403 \\
103\end{array}$ & $\begin{array}{c}40 \\
0\end{array}$ & $\begin{array}{c}33.3 \\
0\end{array}$ & 0.043 \\
\hline $\begin{array}{l}\text { Tumor response } \\
\text { CR } \\
\text { PR } \\
\text { PD } \\
\end{array}$ & $\begin{array}{c}31 \\
11 \\
- \\
\end{array}$ & $\begin{array}{c}636 \\
545.6 \\
- \\
\end{array}$ & $\begin{array}{r}403 \\
103 \\
- \\
\end{array}$ & $\begin{array}{c}42.8 \\
18.2 \\
- \\
\end{array}$ & $\begin{array}{c}32.1 \\
18.2 \\
- \\
\end{array}$ & $\mathbf{0 . 0 3 8}$ \\
\hline
\end{tabular}

$a^{*}$ - non-computable (SPSS system information); $d$ - days; $n$ - number of cats; $p$ - statistical significance. $\mathrm{p}$ values considered significant are listed in bold. 


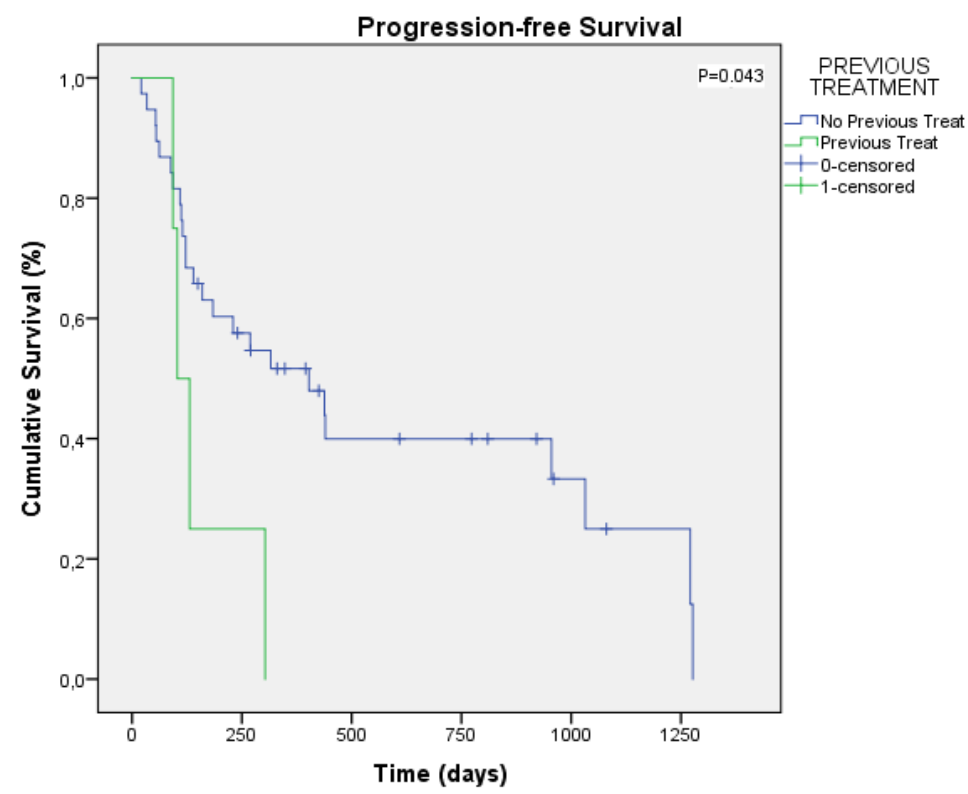

Graph 13 - Kaplan-Meier curve comparing progression-free survival of cats treated with HDR brachytherapy without (blue) and with (green) a previous treatment; $\mathrm{p}=0.043$.

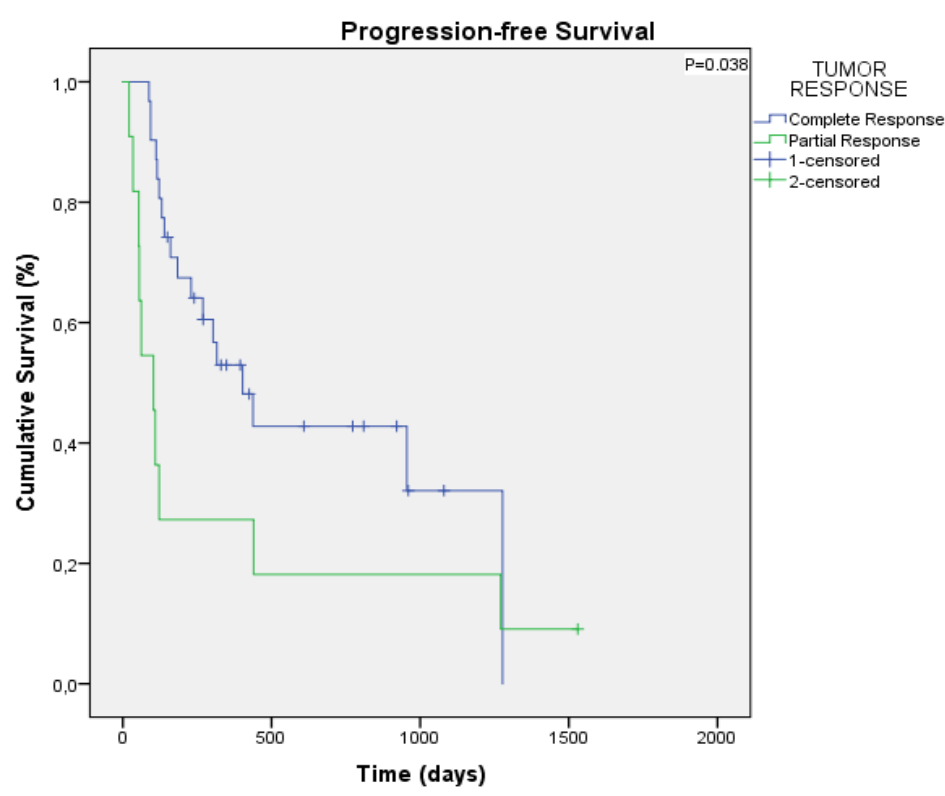

Graph 14 - Kaplan-Meier curve comparing progression-free survival of complete (blue) or partial (green) tumor response to HDR brachytherapy; $\mathrm{p}=0.038$.

\subsection{Overall Survival}

Information about OS was available for 43 cats. The mean and median times of OS were 963 days (95\% CI: 707,417 to 1218,897 ) and 835 days (95\% CI: 84.764 to 1585.236 ), respectively.

Table 5 summarizes the mean and median values of OS and the cumulative survival at day 500 and 1000. From the analysis of the results it was possible to conclude that the gender $(\mathrm{p}=0.045)$, the upper lip extension $(\mathrm{p}=0.015)$, the tumor size $(\mathrm{p}=0.001)$ and the type of 
response to brachytherapy $(\mathrm{p}<0.001)$ were the variables that presented a statistical significant association with OS (Graph 15, Graph 16, Graph 17 and Graph 18).

Table 5 - Relation between variables and overall survival at day 500 and 1000.

\begin{tabular}{|c|c|c|c|c|c|c|}
\hline \multirow[b]{3}{*}{ Variables } & \multicolumn{6}{|c|}{ Overall Survival } \\
\hline & \multirow{2}{*}{$\mathbf{n}$} & \multirow{2}{*}{ Mean (d) } & \multirow{2}{*}{ Median (d) } & \multicolumn{2}{|c|}{ Cumulative survival (\%) } & \multirow[b]{2}{*}{$\mathbf{p}$} \\
\hline & & & & $500 \mathrm{~d}$ & $1000 \mathrm{~d}$ & \\
\hline $\begin{array}{l}\text { Gender } \\
\text { Male } \\
\text { Female }\end{array}$ & $\begin{array}{l}22 \\
21 \\
\end{array}$ & $\begin{array}{c}645.7 \\
1251.6 \\
\end{array}$ & $\begin{array}{c}354 \\
1817 \\
\end{array}$ & $\begin{array}{l}35.6 \\
76.2 \\
\end{array}$ & $\begin{array}{l}29.6 \\
66.7\end{array}$ & 0.045 \\
\hline $\begin{array}{l}\text { Neuter Status } \\
\text { Neutered } \\
\text { Intact }\end{array}$ & $\begin{array}{c}40 \\
1\end{array}$ & $\begin{array}{c}1026.1 \\
269\end{array}$ & $\begin{array}{c}1271 \\
269 \\
\end{array}$ & $\begin{array}{c}58.8 \\
0\end{array}$ & $\begin{array}{c}50.3 \\
0\end{array}$ & 0.269 \\
\hline $\begin{array}{l}\text { Breed } \\
\text { Common European } \\
\text { Turkish } \\
\text { Birman crossed } \\
\end{array}$ & $\begin{array}{c}41 \\
1 \\
1 \\
\end{array}$ & $a^{*}$ & $a^{*}$ & $\begin{array}{c}52.6 \\
- \\
0 \\
\end{array}$ & $\begin{array}{c}44.4 \\
- \\
0 \\
\end{array}$ & 0.811 \\
\hline $\begin{array}{l}\text { Age } \\
\leq 11 \text { years old } \\
>11 \text { years old }\end{array}$ & $\begin{array}{l}22 \\
20 \\
\end{array}$ & $\begin{array}{c}1106.6 \\
790.8 \\
\end{array}$ & $\begin{array}{c}1271 \\
464 \\
\end{array}$ & $\begin{array}{c}65.7 \\
45 \\
\end{array}$ & $\begin{array}{c}59.8 \\
36 \\
\end{array}$ & 0.395 \\
\hline $\begin{array}{l}\text { Number of Lesions } \\
\text { Single } \\
\text { Multiple } \\
\end{array}$ & $\begin{array}{c}34 \\
8 \\
\end{array}$ & $\begin{array}{c}850 \\
1181.3 \\
\end{array}$ & $\begin{array}{c}835 \\
1817 \\
\end{array}$ & $\begin{array}{l}54.4 \\
58.3 \\
\end{array}$ & $\begin{array}{l}45.1 \\
58.3 \\
\end{array}$ & 0.359 \\
\hline $\begin{array}{l}\text { Localization } \\
\text { Nostril wing } \\
\text { Rostral } \\
\text { Dorsal } \\
\text { Combination } \\
\text { Nose tip } \\
\text { Nasal cavity } \\
\end{array}$ & $\begin{array}{c}15 \\
3 \\
3 \\
17 \\
2 \\
1 \\
\end{array}$ & $a^{*}$ & $a^{*}$ & $\begin{array}{c}58.7 \\
66.7 \\
0 \\
36.4 \\
0 \\
0 \\
\end{array}$ & $\begin{array}{c}50.3 \\
0 \\
0 \\
36.4 \\
0 \\
0 \\
\end{array}$ & 0.400 \\
\hline $\begin{array}{l}\text { Hairy skin extension } \\
\text { No } \\
\text { Yes }\end{array}$ & $\begin{array}{c}5 \\
27 \\
\end{array}$ & $\begin{array}{c}770.2 \\
999 \\
\end{array}$ & $\begin{array}{c}464 \\
1271 \\
\end{array}$ & $\begin{array}{c}40 \\
57.2 \\
\end{array}$ & $\begin{array}{c}40 \\
52.8 \\
\end{array}$ & 0.995 \\
\hline $\begin{array}{l}\text { Upper lip extension } \\
\text { No } \\
\text { Yes }\end{array}$ & $\begin{array}{l}20 \\
17\end{array}$ & $\begin{array}{c}1208.6 \\
403.5\end{array}$ & $\begin{array}{c}1817 \\
267 \\
\end{array}$ & $\begin{array}{l}69.6 \\
24.3 \\
\end{array}$ & $\begin{array}{c}64.3 \\
0\end{array}$ & 0.015 \\
\hline $\begin{array}{l}\text { Tumor size } \\
\leq 2 \mathrm{~cm} \\
>2 \mathrm{~cm} \\
\end{array}$ & $\begin{array}{l}15 \\
20 \\
\end{array}$ & $\begin{array}{c}1494.8 \\
523.1 \\
\end{array}$ & $\begin{array}{c}1817 \\
267 \\
\end{array}$ & $\begin{array}{l}86.2 \\
29.5 \\
\end{array}$ & $\begin{array}{l}75.4 \\
23.6 \\
\end{array}$ & 0.001 \\
\hline $\begin{array}{l}\text { Ulceration } \\
\text { Absent } \\
\text { Present } \\
\end{array}$ & $\begin{array}{c}5 \\
35 \\
\end{array}$ & $\begin{array}{c}1301.4 \\
879.1 \\
\end{array}$ & $\begin{array}{l}574 \\
835 \\
\end{array}$ & $\begin{array}{c}80 \\
51.5 \\
\end{array}$ & $\begin{array}{c}80 \\
40.5 \\
\end{array}$ & 0.166 \\
\hline $\begin{array}{l}\text { Lymph node involvement } \\
\text { Absent } \\
\text { Present } \\
\end{array}$ & $\begin{array}{c}15 \\
0 \\
\end{array}$ & $a^{*}$ & $a^{*}$ & $a^{*}$ & $a^{*}$ & $a^{*}$ \\
\hline $\begin{array}{l}\text { Lung metastasis } \\
\text { Absent } \\
\text { Present } \\
\end{array}$ & $\begin{array}{c}33 \\
0 \\
\end{array}$ & $a^{*}$ & $a^{*}$ & $a^{*}$ & $a^{*}$ & $a^{*}$ \\
\hline $\begin{array}{l}\text { Previous treatment } \\
\text { No } \\
\text { Yes } \\
\end{array}$ & $\begin{array}{c}36 \\
4 \\
\end{array}$ & $\begin{array}{c}1071.8 \\
436.8 \\
\end{array}$ & $\begin{array}{c}1271 \\
235 \\
\end{array}$ & $\begin{array}{c}56.2 \\
50 \\
\end{array}$ & $\begin{array}{c}56.2 \\
0 \\
\end{array}$ & 0.058 \\
\hline $\begin{array}{l}\text { Tumor response } \\
\text { CR } \\
\text { PR } \\
\text { PD } \\
\end{array}$ & $\begin{array}{c}30 \\
9 \\
1 \\
\end{array}$ & $\begin{array}{c}1023.8 \\
639 \\
9 \\
\end{array}$ & $\begin{array}{c}- \\
157 \\
9 \\
\end{array}$ & $\begin{array}{c}64.1 \\
33.3 \\
0 \\
\end{array}$ & $\begin{array}{c}50.7 \\
33.3 \\
0 \\
\end{array}$ & $<0.001$ \\
\hline
\end{tabular}

$\mathrm{a}^{*}$ - non-computable (SPSS system information); $\mathrm{d}$ - days; $\mathrm{n}$ - number of cats; $\mathrm{p}$ - statistical significance. $\mathrm{p}$ values considered significant are listed in bold. 
The gender of cats treated with HDR brachytherapy was found to have a statistical significant association with the overall survival $(\mathrm{p}=0.045)$. Male cats showed a median OS of 354 days (95\% CI: 123.589-584.411) and a lower cumulative survival, when compared to female cats that showed a median OS of 1817 days (Graph 15). At day 500, were alive 35.6\% of the males and $76.2 \%$ of the females, and the difference was even more significant at day 1500 , where $29.6 \%$ of the males were alive compared to $53.3 \%$ of the females.

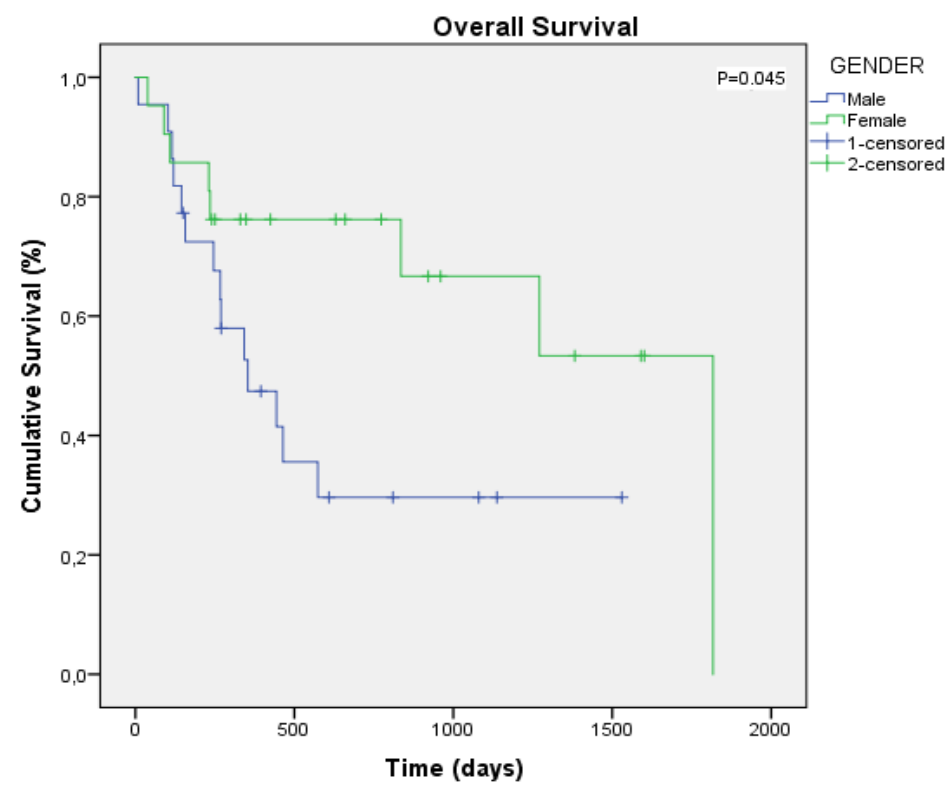

Graph 15 - Kaplan-Meier curve comparing overall survival of male (blue) and female (green) cats treated with HDR brachytherapy; $\mathrm{p}=0.045$.

Extension of the tumor from the nasal planum to the upper lip was found to have a statistical significant association with the overall survival $(\mathrm{p}=0.015)$. Cats with extension to the upper lip showed a median OS of 267 days (95\% CI: 145.437-388.563) and a lower cumulative survival (Graph 16), when compared to the cats without the extension which had a median OS of 1817 days. At day 500, cats with the upper lip affected presented a cumulative survival of $24.3 \%$, compared to $69.6 \%$ of the cats without upper lip affection. At day 1000 all the cats with the upper lip affected were dead while there were still $64.3 \%$ of cats without upper lip affection alive. 


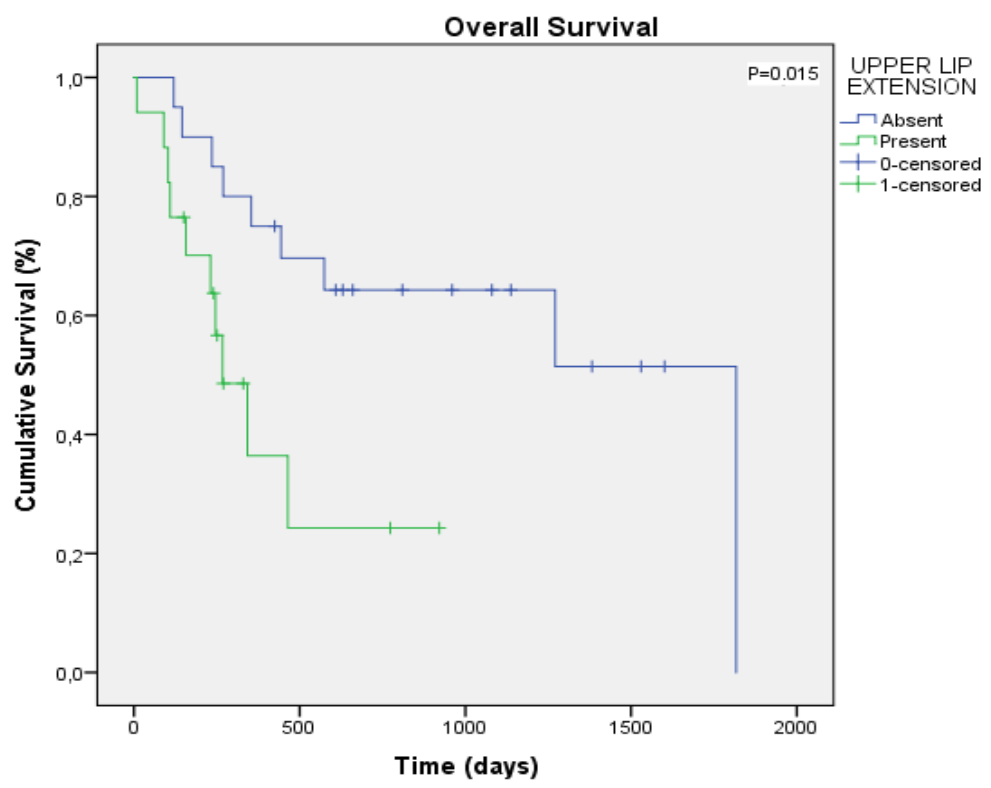

Graph 16 - Kaplan-Meier curve comparing overall survival of cats without (blue) and with (green) extension of the tumor from the nasal planum to the upper lip, treated with HDR brachytherapy; $\mathrm{p}=0.015$.

Tumor size was found to have a statistical significance association with overall survival $(\mathrm{p}=0.001)$. Cats with a tumor size larger than $2 \mathrm{~cm}$ showed a median OS of 267 days $(95 \% \mathrm{CI}$ : 128.708-405.292) and a lower cumulative survival (Graph 17), when compared to the cats with tumors equal or smaller than $2 \mathrm{~cm}$ which had a median OS of 1817 days. At days 500 and 1000, cats with tumor size larger than $2 \mathrm{~cm}$ presented cumulative survivals of $29.5 \%$ and $23.6 \%$, compared to cats with tumor size equal or smaller than to $2 \mathrm{~cm}$ that presented cumulative survivals of $86.2 \%$ and $75.4 \%$, respectively.

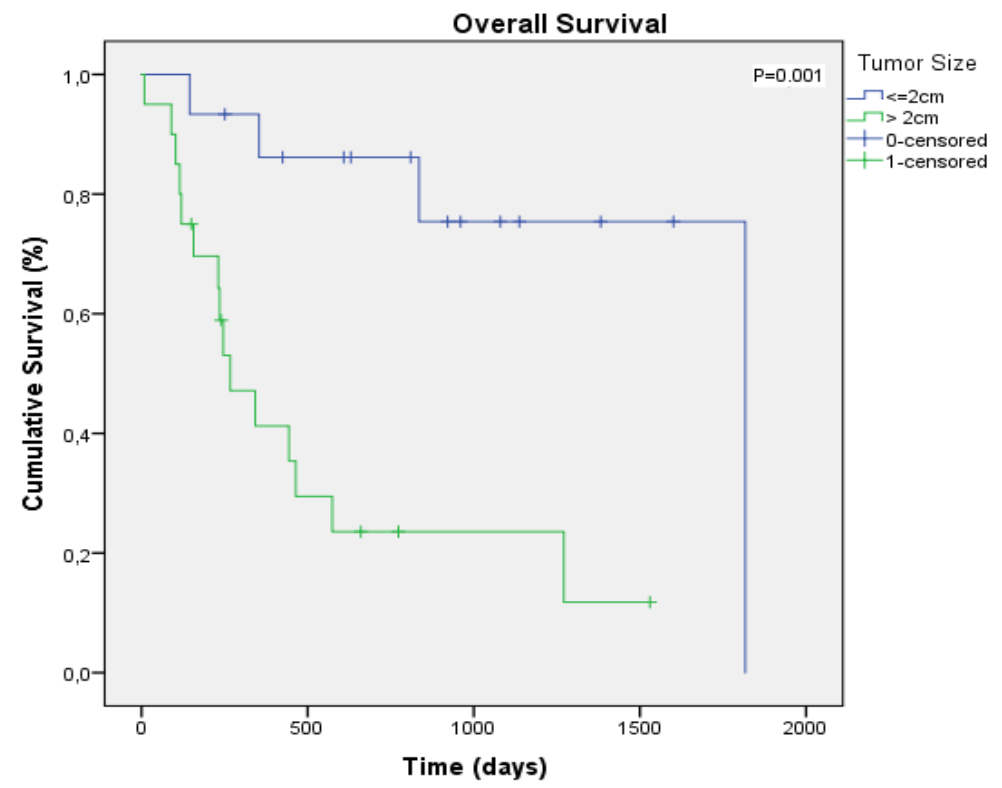

Graph 17 - Kaplan-Meier curve comparing overall survival of cats treated with HDR brachytherapy with a tumor size equal or smaller than $2 \mathrm{~cm}$ (blue) and larger than $2 \mathrm{~cm}$ (green); $\mathrm{p}=0.001$. 
The tumor response to HDR brachytherapy was found to have a statistical significant association with the overall survival $(\mathrm{p}<0.001)($ Graph 18). Cats that experienced CR presented the best prognosis with a mean OS of 1024 days (95\% CI: 767.140 to 1280.554 ) and a cumulative survival of $64.1 \%$ and $50.7 \%$ at day 500 and 1000 , respectively. Cats that presented a PR showed a median OS of 639 days (95\% CI: 135.106 to 1142.894) and a cumulative survival of $33.3 \%$ at day 500 and 1000 .

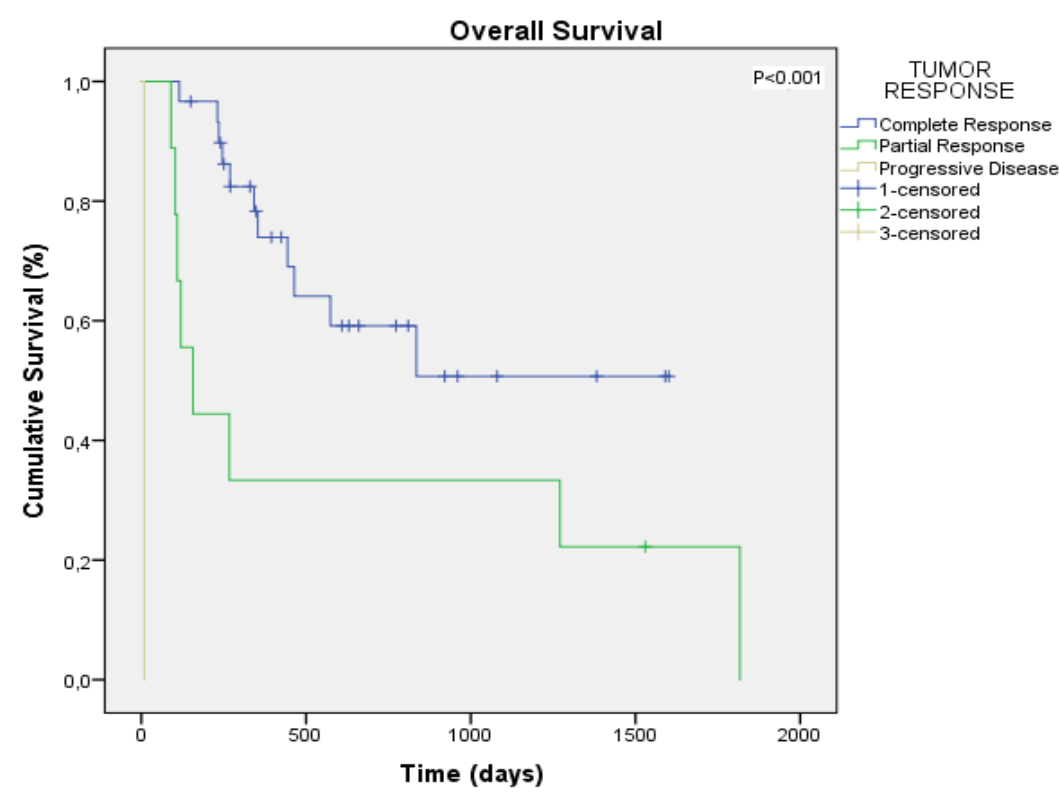

Graph 18 - Kaplan-Meier curve comparing overall survival of complete (blue), partial (green) or progressive (golden) tumor response to HDR brachytherapy; $\mathrm{p}<0.001$. 


\section{DISCUSSION}

Squamous cell carcinoma is the third most common cutaneous tumor in cats and it has been treated with RT for the last years with satisfactory outcomes and results. However, HDR brachytherapy has proved to be a very effective option to local treatment with few side effects. Despite the numerous publications on the use of RT in the management of this tumor, studies on HDR brachytherapy are lacking, and so the results of survival analysis of this work were compared with those of the studies on other RT modalities.

The studied population of 58 cats was almost half divided by gender, with a slight larger number of males than females (ratio male-female of 1.1), a result similar to those already obtained by other authors $7,12,27,29$. These data also supported the inexistence of a gender predisposition to feline SCC, already known from other publications ${ }^{2,27,66}$.

The Common European cats were overrepresented in this study $(96.6 \%, \mathrm{n}=56)$ and so it was not possible to observe if a short-haired breed or any pure breed would be more susceptible, as referenced in the literature ${ }^{2}$. Due to the variety of characteristics and multiple coat colors possible among the Common European cats, these results also sustain the inexistence of a breed predisposition to SCC. ${ }^{2,27,66}$

The mean and median age of the cats in this study was 11 years old. This confirms, once again, the tendency of these tumors to affect older cats (10-12 years old). 2,5,18,22

In this work, a single lesion occurred in the majority of cats $(78.9 \%, n=45)$, in contrast to a 1991 's publication cited by Rassnick ${ }^{1}$, where was reported that multiple lesions were observed in approximately $45 \%$ of the cats with cutaneous SCC even though they were not exclusively in the nasal planum. The lack of homogeneity regarding tumor location in the previous study might be the responsible for the discrepancy in present results.

Regarding the anatomical localization, based on the data from clinical histories, 6 locals were considered, and the nostril wing was most affected localization (33.9\%, $\mathrm{n}=19)$. Considering the nasal planum only, no other study has ever divided it into smaller anatomical parts. This study included too many localizations and difficult to group in less categories, and due to the reduced number of cats per group it was not possible to study the correlation with survival times.

Information about the extension of the tumor from the nasal planum to the hairy skin that surrounded de nasal planum was record because SCC is a locally invasive neoplasm (although slow to metastasize). ${ }^{2,12}$ Extension to the upper lip was thought to be of a bad prognostic not 
only because of the tumor invasive behavior but also because of the presence of squamous epithelium in the skin-mucosa junction. ${ }^{25,30,67}$ In the literature is reported that oral SCC has a poorer prognosis when compared to the cutaneous one, and a higher metastatic rate: in a study published by Soltero-Rivera et al. ${ }^{68}$, metastasis in regional lymph nodes in $15 / 49$ cats with oral SCC were reported, as well as thoracic metastasis in 5/49 cats; additionally, Moore ${ }^{69}$ estimated a median survival time of 2 months for cats with oral SCC treated only with chemotherapy or surgery or RT. The results of the present study support a worse prognosis associated with this characteristic.

In what concerns to the tumor size, and based on the TNM classification system proposed by the $\mathrm{WHO}^{24}$, lesions smaller than $2 \mathrm{~cm}$ are included in the $\mathrm{T}_{\text {is }}$ and $\mathrm{T} 1$ stages, which represent pre-invasive and superficial lesions, without any minimal invasion; lesions larger than $2 \mathrm{~cm}$ and/or with minimal invasion are considered more invasive, aggressive and deeper tumors, ranging from stages T2 to T4. Many studies report lesions that are mostly superior or inferior to $2 \mathrm{~cm}$, so our results are in agreement with those described by other authors.

Ulceration is present when there is a rupture of the basal membrane of the epidermis, resulting in a total loss of epidermis and dermis exposure. ${ }^{8}$ Given the invasive character of SCC it is not surprising that ulceration was present in the majority $(83.6 \%, n=46)$ of the lesions, although without any prognostic value. A variety of publications report the usual observation of ulceration in nasal planum SCC. - $4,10,25,26,39,40,44,63,66,70^{2}$

Nasal planum SCC has a low metastatic rate ${ }^{2,5}$, not only at distance but also to the regional lymph nodes, which is verified in this study with all cats with a locally staged tumor. However, there are some reports of the presence of regional or distant metastasis. ${ }^{15,27}$

After the first HDR brachytherapy tumor response was evaluated. The majority of the cats (72\%, $\mathrm{n}=36$ ) achieved a $\mathrm{CR}$, and it was satisfactory compared to those for tumor response to external RT. ${ }^{12,15,26,27,39,62}$ In some cases $(26 \%, n=13)$ PR was observed, as well as PR was also observed in other publications although with a wider range of values. ${ }^{12,26,62,63}$ There was 1 cat $(2 \%)$ in this study that showed a PD, but in other publications using RT there were cases in which the tumor did not respond to therapy too. ${ }^{15,62}$

Tumor recurrence was observed in $67.4 \%(n=29)$ of the cats. The possible occurrence of new lesions in the nasal planum but not exactly in the same place of the treated tumor is difficult to discern, and even harder if it is a different veterinarian to evaluate, which happens often due to the reference to other facilities for RT. These limitations were also mentioned in the publication of Hammond et al. ${ }^{12}$, and moreover, the possibility of an overestimation of the 
recurrence times since the owners could notice the new lesion, or a progression of a stable lesion, and not reporting it to their vet immediately, wrongly extending the PFS times. Additionally, the tumor volume is very important in what concerns to treat a tumoral lesion with clear margins, and a clear assessment of the tumor volume can be challenging if threedimensional tests (such as CT scan) are not performed, and therefore recurrences at the margins of the treated area can be observed. Recurrence is reported in studies using external RT treatment protocols ${ }^{15,27,29,39,62}$, where it ranged from $11.1 \%$ to $70 \%$.

Regarding the clinical characteristics studied and the tumor response to brachytherapy, only the tumor size showed a statistically significant association $(\mathrm{p}=0.015)$. Thus, the majority of the tumors equal or smaller than $2 \mathrm{~cm}(94.1 \%, \mathrm{n}=16)$ showed a CR to brachytherapy, and only $5.9 \%(\mathrm{n}=1)$ showed a PR. For tumors larger than $2 \mathrm{~cm}$, response to brachytherapy was divided in CR $(52 \%, \mathrm{n}=13), \mathrm{PR}(44 \%, \mathrm{n}=11)$ and PD $(2.4 \%, \mathrm{n}=1)$. These results are in accordance to what Cunha et al. ${ }^{15}$ published, that $\mathrm{T} 1$ lesions showed better treatment responses (CR in $62.5 \%$ ), compared to T3 and T4 lesions (CR in $31.25 \%$ ).

Regarding the clinical characteristics studied and tumor recurrence, none of the variables showed a statistically significant association. But in what concerns to tumor size, although there was not a significant association $(\mathrm{p}=0.107)$, it could be observed that $81.1 \%(\mathrm{n}=18)$ of the tumors larger than $2 \mathrm{~cm}$ showed recurrence and $18.2 \%(\mathrm{n}=4)$ did not, while $57.1 \%(\mathrm{n}=8)$ of the smaller tumors showed recurrence and $42.9 \%(n=6)$ did not. So, our data show a tendency for recurrence in tumors larger than $2 \mathrm{~cm}$ treated with HDR brachytherapy in comparison with smaller tumors (median PFS of 184 days versus 1032 days, respectively). Furthermore, it is reported in the literature that minimally invasive lesions have better tumor control times with a possible long-term control, contrarily to the unsatisfactory results associated with larger and more invasive SCC lesions. ${ }^{1}$

The gender was curiously found to affect OS time. This association has been described in human medicine where some studies identified men at higher risk of cutaneous SCC. ${ }^{71,72}$

Although two groups of ages were considered based on the median value, and despite the agreement of this median value with the literature ${ }^{2,5,18,22}$, age did not show any association with survival times.

Based on what has been discussed previously, extension to the upper lip was thought to be a prognostic factor for the cats of this study, which was confirmed at the end with a statistical significant effect on cats' OS ( $\mathrm{p}=0.015)$. Cats with the upper lip affected lived significantly less 
than those cats without upper lip affection (median OS 267 days versus 1817 days). This aspect has never been described before and represents a new clinical promising prognostic factor.

The tumor size was also found to be statistically associated with the OS $(\mathrm{p}=0.001)$ and so cats with tumors equal or smaller than $2 \mathrm{~cm}$ lived significantly longer than cats with larger lesions (median OS of 1817 days versus 267 days). Almost all the results related to the tumor size are in line with the already published by Théon et al. ${ }^{7}$ that the stage (tumor volume) is a prognostic factor for RT treatment efficacy. In fact cats with smaller SCC of the nasal planum (stage T1) have better prognosis and longer PFS than cats with larger lesions (stages T3 and T4). ${ }^{7}$

At the end, the existence of a previous treatment showed a statistically significant association with PFS. Cats that did not receive a previous treatment showed a better local tumor control and longer median PFS (403 days versus 103 days) ( $p=0.043)$. Even though the observed clear tendency of a previous treatment to worse OS times (median OS 235 days versus 1271 days), data did not reach the statistical significance ( $\mathrm{p}=0.058)$. These results do not mean that HDR brachytherapy is not effective, but somehow in these heavily treated tumors a previous treatment can reduce the response to HDR brachytherapy. This is the first study in which this association was studied and therefore it was not possible to compare to the veterinary literature.

Tumor response to brachytherapy was found to be statistically associated with PFS $(\mathrm{p}=0.038)$ and showed a highly significant association with OS $(\mathrm{p}<0.001)$. Cats that achieved a CR showed longer local tumor control times (median PFS 403 days for CR versus 103 days for PR) and lived longer (mean OS 1023 days for CR versus 639 days for PR). These results are consistent with the reported by Hammond et al. ${ }^{12}$ that cats with CR had a longer OS than cats with PR ( $<<0.001)$, apart from the fact that the brachytherapy treatment used was not the same.

The protocol used in this study is more advantageous than those used in external RT that requires, in average, three general anesthesias per week, over a period of 3 to 4 weeks. Using this protocol, treatment was usually performed during a one-week period, requiring only sedation and monitoring of vital signs for each session. The advantages of this treatment are the short overall treatment time, the convenience for the owner to leave their cat at the clinic and the treatment be done in 3 to 4 days, the relative cost and a mean OS of 963 days (2.6 years) after the treatment. From the practical experience of performing HDR brachytherapy, acute skin effects grade 1 to 2 (according the VRTOG score ${ }^{51}$ ) can be observed during a few days 
following treatment . A long-term follow-up after treatment should be carried on for 2 years, with a regular clinical monitoring of the treated area and palpation of the regional lymph nodes. 


\section{CONCLUSION}

In conclusion, this study demonstrated that brachytherapy is advantageous in the treatment of feline SCC of the nasal planum, allowing a proper delivery of radiation to the neoplastic tissue and reducing the toxic radiation related effects on the surrounding non-neoplastic tissue.

This retrospective study also showed that male cats and older cats were the most affected by this tumor, and that the complete response rate of $72 \%$ was in accordance with the expectations.

Of the variables studied, five of them showed to be of prognostic value for treatment with HDR brachytherapy. The gender of the cats treated with HDR brachytherapy was correlated with OS time and male cats lived significantly less than females. Tumor extension from the nasal planum to the upper lip was for the first time found to affect the OS: cats without the upper lip affected lived significantly longer than cats with the upper lip affected. Tumor size showed a significant effect on tumor response: tumors equal or smaller than $2 \mathrm{~cm}$ achieved a better treatment responses. Tumor size also revealed a statistical significant effect on OS: cats with tumors equal or smaller than $2 \mathrm{~cm}$ lived longer than cats with larger lesions. A previous treatment was found to correlate with PFS, and cats that received other treatment before the HDR brachytherapy showed shorter PFS times than the cats that did not receive any treatment before the brachytherapy. Finally, tumor response to HDR brachytherapy was also found to be statistically associated with PFS and OS, so cats with better tumor responses showed better local tumor control times and lived longer.

Our data indicate that to better manage cats' SCC of the nasal planum, lesions should be treated as soon as possible and can be achieved very good results with HDR brachytherapy in what concerns to PFS and OS. 


\section{REFERENCES}

1. Rassnick KM. Tumors of the Skin. In: Ettinger SJ, Feldman EC, Côté E, eds. Textbook of Veterinary Internal Medicine. eighth. Elsevier; 2017:5033-5045.

2. Murphy S. Cutaneous squamous cell carcinoma in the cat: current understanding and treatment approaches. $J$ Feline Med Surg. 2013;15(5):401-407. doi:10.1177/1098612X13483238.

3. Gill VL, Bergman PJ, Baer KE, Craft D, Leung C. Use of imiquimod 5\% cream (Aldara) in cats with multicentric squamous cell carcinoma in situ: 12 cases (2002-2005). Vet Comp Oncol. 2008;6(1):55-64. doi:10.1111/j.1476-5829.2007.00144.x.

4. Munday JS, Dunowska M, De Grey S. Detection of two different papillomaviruses within a feline cutaneous squamous cell carcinoma: case report and review of the literature. N Z Vet J. 2009;57(4):248-251. doi:10.1080/00480169.2009.36911.

5. Hauck ML. Tumors of the Skin and Subcutaneous Tissues. In: Withrow and MacEwen's Small Animal Clinical Oncology. 5th ed. Elsevier/Saunders; 2013:305-320.

6. Hayes AM, Adams VJ, Scase TJ, Murphy S. Survival of 54 cats with oral squamous cell carcinoma in United Kingdom general practice. J Small Anim Pract. 2007;48(7):394399. doi:10.1111/j.1748-5827.2007.00393.x.

7. Théon AP, Madewell BR, Shearn VI, Moulton JE. Prognostic factors associated with radiotherapy of squamous cell carcinoma of the nasal plane in cats. $J$ Am Vet Med Assoc. 1995;206(7):991-996.

8. Hargis AM, Ginn PE. The Integument. In: McGavin MD, Zachary JF, eds. Pathologic Basis of Veterinary Disease. fourth. Mosby Elsevier; 2007:1107-1262.

9. Withrow SJ. Tumors of the Respiratory System. In: Withrow and MacEwen's Small Animal Clinical Oncology. 5th ed. Elsevier/Saunders; 2013:432-462.

10. Ayres SA, Liptak JM, Kudnig ST, Séguin B. Head and Neck Tumors. In: Kudnig ST, Seguin B, eds. Veterinary Surgical Oncology. West Sussex, UK: John Wiley \& Sons, Ltd,.; 2012:87-117. doi:10.1002/9781118729038.ch5.

11. Munday JS, Gibson I, French AF. Papillomaviral DNA and increased p16CDKN2A protein are frequently present within feline cutaneous squamous cell carcinomas in ultraviolet-protected skin. Vet Dermatol. 2011;22(4):360-366. doi:10.1111/j.13653164.2011.00958.x.

12. Hammond GM, Gordon IK, Theon AP, Kent MS. Evaluation of strontium Sr 90 for the 
treatment of superficial squamous cell carcinoma of the nasal planum in cats: 49 cases (1990-2006). J Am Vet Med Assoc. 2007;231(5):736-741. doi:10.2460/javma.231.5.736.

13. LeBlanc AK. Neoplastic and Nonneoplastic Tumors. In: Hnilica KA, ed. Small Animal Dermatology: A Color Atlas and Therapeutic Guide. 3rd ed. Saunders Elsevier; 2011:428-489.

14. Ravens PA, Vogelnest LJ, Tong LJ, Demos LE, Bennett MD. Papillomavirus-associated multicentric squamous cell carcinoma in situ in a cat: an unusually extensive and progressive case with subsequent metastasis. Vet Dermatol. 2013;24(6):642-645, e1612. doi:10.1111/vde.12080.

15. Cunha SCS, Carvalho LA V., Canary PC, et al. Radiation therapy for feline cutaneous squamous cell carcinoma using a hypofractionated protocol. J Feline Med Surg. 2010;12(4):306-313. doi:10.1016/j.jfms.2009.10.005.

16. Hayes A, Scase T, Miller J, Murphy S, Sparkes A, Adams V. COX-1 and COX-2 Expression in Feline Oral Squamous Cell Carcinoma. J Comp Pathol. 2006;135(2):9399. doi:10.1016/j.jcpa.2006.06.001.

17. Boyé P, Benoit J. Prise en charge des tumeurs nasales chez le chien et le chat. Le point Vétérinaire. 2016:36-41.

18. Blackwood L. Tumors of the skin and subcutaneous tissues. In: Dobson JM, Lascelles BDX, eds. BSAVA Manual of Canine and Feline Oncology. 3rd ed. BSAVA; 2011:130158.

19. Lascelles BDX. Tumours of the respiratory system and thoracic cavity. In: Dobson JM, Lascelles BDX, eds. BSAVA Manual of Canine and Feline Oncology. 3rd ed. BSAVA; 2011:265-284.

20. Northrup N. Tumors of the Skin, Subcutis, and Other Soft Tissues. In: Henry CJ, Higginbotham ML, eds. Cancer Management in Small Animal Practice. Saunders Elsevier; 2010:299-332.

21. Oechtering GU. Diseases of the Nose, Sinuses, and Nasopharynx. In: Ettinger SJ, Feldman EC, Côté E, eds. Textbook of Veterinary Internal Medicine. eighth. Elsevier; 2017:2621-2658.

22. North S, Banks TA. Tumours of head and neck. In: North S, Banks TA, eds. Introduction to Small Animal Oncology. Saunders Elsevier; 2009:91-114.

23. Tromblee TC, Jones JC, Etue AE, Forrester SD. Association between clinical characteristics, computed tomography characteristics, and histologic diagnosis for cats 
with sinonasal disease. Vet Radiol Ultrasound. 47(3):241-248.

24. Owen L. TNM classification of tumours in domestic animals. 1980.

25. Tozon N, Pavlin D, Sersa G, Dolinsek T, Cemazar M. Electrochemotherapy with intravenous bleomycin injection: an observational study in superficial squamous cell carcinoma in cats. $J$ Feline Med Surg. 2014;16(4):291-299. doi:10.1177/1098612X13507071.

26. Goodfellow M, Hayes A, Murphy S, Brearley M. A retrospective study of (90)Strontium plesiotherapy for feline squamous cell carcinoma of the nasal planum. J Feline Med Surg. 2006;8(3):169-176. doi:10.1016/j.jfms.2005.12.003.

27. Melzer K, Guscetti F, Rohrer Bley C, Sumova A, Roos M, Kaser-Hotz B. Ki67 reactivity in nasal and periocular squamous cell carcinomas in cats treated with electron beam radiation therapy. J Vet Intern Med. 2006;20(3):676-681.

28. LaRue SM, Gordon IK. Radiation Therapy. In: Withrow and MacEwen's Small Animal Clinical Oncology. 5th ed. Elsevier/Saunders; 2013:180-197. doi:10.1016/B978-1-43772362-5.00012-8.

29. Carlisle $\mathrm{CH}$, Gould S. Response of squamous cell carcinoma of the nose of the cat to treatment with $\mathrm{X}$ rays. Vet Radiol. 1982;23(5):186-192. doi:10.1111/j.17408261.1982.tb01279.x.

30. Thomson M. Squamous cell carcinoma of the nasal planum in cats and dogs. Clin Tech Small Anim Pract. 2007;22(2):42-45. doi:10.1053/j.ctsap.2007.03.002.

31. Baba AI, Câtoi C. Principles of anticancer therapy. In: Comparative Oncology. Bucharest: The Publishing House of the Romanian Academy; 2007.

32. Withrow S, Straw R. Resection of the nasal planum in nine cats and five dogs. $J$ Am Anim Hosp Assoc. 1990;26(Mar/Apr):219-222.

33. Bexfield NH, Stell AJ, Gear RN, Dobson JM. Photodynamic therapy of superficial nasal planum squamous cell carcinomas in cats: 55 cases. $J$ Vet Intern Med. 22(6):1385-1389. doi:10.1111/j.1939-1676.2008.0186.x.

34. Buchholz J, Wergin M, Walt H, Gräfe S, Bley CR, Kaser-Hotz B. Photodynamic therapy of feline cutaneous squamous cell carcinoma using a newly developed liposomal photosensitizer: preliminary results concerning drug safety and efficacy. J Vet Intern Med. 2007;21(4):770-775.

35. Buchholz J, Walt H. Veterinary photodynamic therapy: A review. Photodiagnosis Photodyn Ther. 2013;10(4):342-347. doi:10.1016/j.pdpdt.2013.05.009. 
36. Magne ML, Rodriguez CO, Autry SA, Edwards BF, Theon AP, Madewell BR. Photodynamic therapy of facial squamous cell carcinoma in cats using a new photosensitizer. Lasers Surg Med. 1997;20(2):202-209.

37. Ferreira I, Rahal SC, Rocha NS, et al. Hematoporphyrin-based photodynamic therapy for cutaneous squamous cell carcinoma in cats. Vet Dermatol. 2009;20(3):174-178. doi:10.1111/j.1365-3164.2009.00743.x.

38. Stell AJ, Dobson JM, Langmack K. Photodynamic therapy of feline superficial squamous cell carcinoma using topical 5-aminolaevulinic acid. J Small Anim Pract. 2001;42(4):164-169.

39. de Vos JP, Burm AGO, Focker BP. Results from the treatment of advanced stage squamous cell carcinoma of the nasal planum in cats, using a combination of intralesional carboplatin and superficial radiotherapy: a pilot study. Vet Comp Oncol. 2004;2(2):7581. doi:10.1111/j.1476-5810.2004.00040.x.

40. Théon AP, VanVechten MK, Madewell BR. Intratumoral administration of carboplatin for treatment of squamous cell carcinomas of the nasal plane in cats. Am J Vet Res. 1996;57(2):205-210.

41. Lanore D, Delprat C. Quimioterapia Anticancerígena. first. São Paulo: Roca Ltda.; 2004.

42. Spugnini EP, Vincenzi B, Citro G, et al. Electrochemotherapy for the treatment of squamous cell carcinoma in cats: a preliminary report. Vet J. 2009;179(1):117-120. doi:10.1016/j.tvj1.2007.08.011.

43. Beam SL, Rassnick KM, Moore AS, McDonough SP. An Immunohistochemical Study of Cyclooxygenase-2 Expression in Various Feline Neoplasms. Vet Pathol. 2003;40(5):496-500. doi:10.1354/vp.40-5-496.

44. Bardagí M, Fondevila D, Ferrer L. Immunohistochemical detection of COX-2 in feline and canine actinic keratoses and cutaneous squamous cell carcinoma. J Comp Pathol. 2012;146(1):11-17. doi:10.1016/j.jcpa.2011.03.012.

45. McEntee MC. Veterinary Radiation Therapy: Review and Current State of the Art. J Am Anim Hosp Assoc. 2006;42(2):94-109. doi:10.5326/0420094.

46. Argyle DJ, Brearley M, Turek MM, Roberts L. Cancer Treatment Modalities. In: Decision Making in Small Animal Oncology. Wiley-Blackwell; 2008:69-128.

47. Lawrence J. Principles and Practice of Radiation Oncology. In: Ettinger SJ, Feldman EC, Côté E, eds. Textbook of Veterinary Internal Medicine. eighth. Elsevier; 2017:49404969. 
48. Page RL, Thrall DE. Clinical Indications and Applications of Radiotherapy and Hyperthermia in Veterinary Oncology. Vet Clin North Am Small Anim Pract. 1990;20(4):1075-1092. doi:10.1016/S0195-5616(90)50085-6.

49. Farrelly J, McEntee MC. Principles and applications of radiation therapy. Clin Tech Small Anim Pract. 2003;18(2):82-87. doi:10.1053/svms.2003.36620.

50. Stone HB, Coleman CN, Anscher MS, McBride WH. Effects of radiation on normal tissue: consequences and mechanisms. Lancet Oncol. 2003;4(9):529-536.

51. Ladue T, Klein MK. TOXICITY CRITERIA OF THE VETERINARY RADIATION THERAPY ONCOLOGY GROUP. Vet Radiol Ultrasound. 2001;42(5):475-476. doi:10.1111/j.1740-8261.2001.tb00973.x.

52. Vechten MK Van, Theon AP. Strontium-90 Plesiotherapy For Treatment Of Early Squamous Cell Carcinomas Of The Nasal Planum In 25 Cats. In: Veterinary Cancer Society Proceedings, 13th Annual Conference. ; 1993:107-108.

53. Lepault S. Le traitement des tumeurs du complexe fibrosarcome felin par curietherapie (Iridium-192): Etude retrospective sur 252 chats traites entre 2000 et 2004. 2009.

54. Turrel JM, Koblik PD. TECHNIQUES OF AFTERLOADING IRIDIUM-192 INTERSTITIAL BRACHYTHERAPY IN VETERINARY MEDICINE. Vet Radiol. 1983;24(6):278-283. doi:10.1111/j.1740-8261.1983.tb00733.x.

55. Walker MA. Interstitial implant brachytherapy in small animals. Vet Clin North Am Small Anim Pract. 1997;27(1):59-71.

56. Klueter S, Krastel D, Ludewig E, et al. High-dose-rate brachytherapy for intranasal tumours in dogs: results of a pilot study. Vet Comp Oncol. 2006;4(4):218-231. doi:10.1111/j.1476-5829.2006.00109.x.

57. Lattimer J, Bommarito D, Bryan J, Brawner W, Almond G. Radiation Therapy. In: Henry CJ, Higginbotham ML, eds. Cancer Management in Small Animal Practice. Saunders Elsevier; 2010:146-156. doi:10.1016/B978-1-4160-3183-3.10015-8.

58. Jumeau R, Renard-oldrini S, Courrech F, Buchheit I, Oldrini G, Vogin G. High dose rate brachytherapy with customized applicators for malignant facial skin lesions. Cancer / Radiother. 2016;20(5):341-346. doi:10.1016/j.canrad.2016.03.008.

59. Peiffert D, Hannoun-Lévi J-M, Oldrini S, Brunaud C. Arrêt de la commercialisation des fils d'iridium 192 en France: proposition du groupe de curiethérapie de la Société française de radiothérapie oncologique. Cancer/Radiothérapie. 2014;18(5-6):441-446. doi:10.1016/j.canrad.2014.08.001. 
60. Hannoun-Lévi JM, Peiffert D. Dose rate in brachytherapy using after-loading machine: Pulsed or high-dose rate? Cancer/Radiotherapie. 2014;18(5-6):437-440. doi:10.1016/j.canrad.2014.07.156.

61. World Health Organization. Remote-afterloading brachytherapy system. http://www.who.int/medical_devices/innovation/remote_afterloading_brachytherapy.p df. Published 2011.

62. Fidel JL, Egger E, Blattmann H, Oberhänsli F, Kaser-Hotz B. Proton irradiation of feline nasal planum squamous cell carcinomas using an accelerated protocol. Vet Radiol Ultrasound. 2001;42(6):569-575.

63. Trivillin VA, Heber EM, Rao M, et al. Boron neutron capture therapy (BNCT) for the treatment of spontaneous nasal planum squamous cell carcinoma in felines. Radiat Environ Biophys. 2008;47(1):147-155. doi:10.1007/s00411-007-0138-8.

64. Rao M, Trivillin VA, Heber EM, et al. BNCT of 3 cases of spontaneous head and neck cancer in feline patients. Appl Radiat Isot. 2004;61(5):947-952. doi:10.1016/j.apradiso.2004.05.016.

65. Carvalho MI, Pires I, Prada J, Lobo L, Queiroga FL. Ki-67 and PCNA Expression in Canine Mammary Tumors and Adjacent Nonneoplastic Mammary Glands. Vet Pathol. 2016;53(6):1138-1146. doi:10.1177/0300985816646429.

66. Favrot C, Welle M, Heimann M, Godson DL, Guscetti F. Clinical, Histologic, and Immunohistochemical Analyses of Feline Squamous Cell Carcinoma In Situ. Vet Pathol. 2009;46(1):25-33. doi:10.1354/vp.46-1-25.

67. Fujiwara-Igarashi A, Fujimori T, Oka M, et al. Evaluation of outcomes and radiation complications in 65 cats with nasal tumours treated with palliative hypofractionated radiotherapy. Vet J. 2014;202(3):455-461. doi:10.1016/j.tvj1.2014.09.016.

68. Soltero-Rivera MM, Krick EL, Reiter AM, Brown DC, Lewis JR. Prevalence of regional and distant metastasis in cats with advanced oral squamous cell carcinoma: 49 cases (2005-2011). J Feline Med Surg. 2014;16(2):164-169. doi:10.1177/1098612X13502975.

69. Moore AS. Treatment choices for oral cancer in cats. What is possible? What is reasonable? J Feline Med Surg. 2009;11(1):23-31. doi:10.1016/j.jfms.2008.11.010.

70. Jarrett RH, Norman EJ, Gibson IR, Jarrett P. Curettage and diathermy: a treatment for feline nasal planum actinic dysplasia and superficial squamous cell carcinoma. $J$ Small Anim Pract. 2013;54(2):92-98. doi:10.1111/jsap.12025. 
71. Kuklinski LF, Zens MS, Perry AE, Gossai A, Nelson HH, Karagas MR. Sex hormones and the risk of keratinocyte cancers among women in the United States: A populationbased case-control study. Int J cancer. 2016;139(2):300-309. doi:10.1002/ijc.30072.

72. Thomas-Ahner JM, Wulff BC, Tober KL, Kusewitt DF, Riggenbach JA, Oberyszyn TM. Gender differences in UVB-induced skin carcinogenesis, inflammation, and DNA damage. Cancer Res. 2007;67(7):3468-3474. doi:10.1158/0008-5472.CAN-06-3798. 
